\title{
Prosodic Structure in Child French: Evidence for the Foot ${ }^{*}$
}

\author{
Heather Goad \\ Meaghen Buckley \\ McGill University. Department of Linguistics \\ 1085 Dr. Penfield. Montreal, Quebec (Canada)
}

\begin{abstract}
There is disagreement in the literature on whether French has stress and on whether it has a foot projection. The disagreement stems from the observation that French is unusual in that the phrase rather than the word is the domain of stress assignment, there is optional initial stress in addition to obligatory final stress, and there are rampant violations of word minimality. In view of these observations, this paper examines the outputs of a child learner of Québec French in an attempt to determine the conclusions she has arrived at concerning the status of the foot in the language being acquired. It is demonstrated that, in spite of the challenge that the facts of the target language present, from the onset of production, the child's outputs are compatible with standard views on prosodic structure. Word minimality effects, the distribution of final lengthening, the emergence of word-final consonants, and the organisation of functional material into prosodic structure are all examined. The paper also provides a preliminary analysis of stress in target French which is, to the greatest extent possible, consistent with standard views on prosodic structure.
\end{abstract}

Key words: French, Québec French, language acquisition, stress, foot binarity, word minimality, truncation, prosodic structure

\section{Table of Contents}

1. Introduction 5 . Word minimality in Clara's grammar

2. Stress in French 6. The lexical/functional split

3. Earlier evidence for the foot 7. Conclusion in child QF

4. Overview of data source and stages References

* This research was supported through grants from FCAR/FQRSC and SSHRC. We would like to thank Katherine Demuth, Anna Gavarró, Imme Kuchenbrandt, Conxita Lleó, Annie Lord, and Yvan Rose for comments and/or for answering our many questions by e-mail. We also gratefully acknowledge the comments of two anonymous reviewers. 


\section{Introduction}

There is disagreement in the literature on whether French has stress and, indeed, on whether it has a foot projection at all. If French has feet, the language is best analysed as involving a single iambic foot at the right edge (Charette 1991). However, virtually all of the properties which typically define iambic systems are absent from the language: the canonical iambic foot is quantitatively uneven, which is arguably not the case for French (see note 2), and iambic languages favour left-toright iterative foot construction (Hayes 1995). An additional complication is the observation that «stress» in French is assigned to the last syllable in the phonological phrase (PPh) (Dell 1984), not the prosodic word (PWd) as it is in the vast majority of languages (e.g., Hayes 1995). Given standard approaches to prosodic structure, where the foot is organised into the PWd, it is not immediately obvious how to ensure that only the rightmost PWd in the PPh bears stress, without including rampant destressing rules for words in non-phrase-final position (cf. Dell 1984) or without violating well-formedness conditions on prosodic constituency (Selkirk 1984, 1986, McCarthy and Prince 1986, Nespor and Vogel 1986). Equally problematic is the observation that French freely violates word minimality, the requirement that lexical words be minimally one binary foot to be well-formed (McCarthy and Prince 1986); subminimal (monomoraic) words abound in the language (e.g., [le] lait 'milk', [gri] gris 'grey-MASC'). If there were no foot in French and «stress» were instead phrase-final prominence, these observations would follow straightforwardly.

From the point of view of early acquisition, the possibility that some adult languages without a foot projection exist may be desirable, as children's earliest outputs across many languages show a strong preference for CV words (Jakobson 1941/68, Ingram 1978, Fikkert 1994). This preference is difficult to motivate on the basis of adult language behaviour as outputs of this shape are subminimal, and most adult languages that permit violations of word minimality do so only under limited conditions. Accordingly, if children's grammars reflect what is cross-linguistically unmarked (Jakobson 1941/68, Stampe 1969, Gnanadesikan 1995/2004), then for monosyllabic targets, foot well-formedness should prefer outputs of the shape CVV, CVC or CVCV, not CV. If, however, there are adult languages for which the absence of a foot projection can be motivated, French being a logical choice to consider, then this constituent will not be projected in the initial state grammar $^{1}$ and syllable well-formedness will first favour CV outputs. In short, the possibility that French lacks feet is significant for all early grammars, as it may lead to a formal account of the otherwise intractable CV stage in acquisition.

In light of this and the challenge that French «stress» presents for the linguist, this paper examines the outputs of one learner of Québec French, Clara (see Rose

1. This is in contrast to many works in Optimality Theory (OT), where it is assumed that all prosodic structure is present from the onset of acquisition, and where the effect of an impoverished prosodic hierarchy is left entirely to constraint ranking (e.g., Demuth 1995, Pater 1997; cf. Goad 1996). The problem in this case is that any constraint which favours CV words (e.g., alignment) cannot be motivated on the basis of adult language behaviour. 
2000), in an attempt to determine what conclusions she has arrived at concerning the status of the foot in French. On the basis of the above discussion, we might have expected Clara's outputs to display rampant violations of word minimality. Counter to expectation, we will demonstrate that, from the onset of production, Clara builds a binary iambic foot at the right edge of the $\mathrm{PWd} / \mathrm{PPh}$ (the $\mathrm{PWd}$ and $\mathrm{PPh}$ are initially co-extensive). Indeed, her outputs are compatible with standard views on prosodic structure, including the organisation of constituents and constituent binarity. Given this finding, an important goal of the paper is to provide an analysis of stress in French which is, to the greatest extent possible, consistent with standard views on prosodic structure. We turn to this issue first.

\section{Stress in French}

\subsection{Observations}

French is traditionally described as having prominence on the rightmost syllable containing a full-vowelled (non-schwa) nucleus in the phrase, where prominence involves both greater duration and higher pitch (Fouché 1934, Garde 1968). The precise formal nature of this «prominence», however, is disputed. Some scholars have interpreted prominence as evidence for foot structure: an iambic foot is built at the right edge of the phrase (Charette 1991, Scullen 1997). Others have assumed that French has no feet at all (Verluyten 1982, Mertens 1987, Jun and Fougeron 2000), and «stress» is instead formally a phrase-final effect.

An additional complicating factor is the observation that prominence is not restricted to phrase-final position. Some researchers have argued that French is characterised by both initial and final prominence (e.g., Gendron 1966 for Québec French (QF); Mertens 1987 for European French (EF)); others have interpreted initial prominence as secondary stress (Paradis and Deshaies 1990, Scullen 1997). Part of the challenge involved in formally characterising the system stems from the observation that these accents differ in a number of ways. First, the initial accent is optional, while the final accent is always realised (Paradis and Deshaies 1990 for QF; Jun and Fougeron 2000 and Post 2003 for EF). Second, different phonetic cues are associated with each accent. As is characteristic of iambic systems, the final accent is principally realised through increased length on the vowel (Walker 1984 for QF; Delattre 1966 for EF); this vowel is also typically assigned a high tone (Ouellet and Thibault 1996 for QF; Jun and Fougeron 2000 for EF). More like trochaic systems, however, the initial accent does not involve lengthening, but is instead marked by a high tone on the first or second syllable of the syntactic constituent (Mertens 1987, Jun and Fougeron 2000). Representative examples are provided in (1). ${ }^{2}$

2. We have not transcribed the final vowels in (1) as long as we do not believe that the increased duration observed on these vowels warrants the addition of a mora. This position is supported through a comparison of the relative duration values of final stressed open syllables and non-final unstressed open syllables in French in contrast to English where final stressed syllables are indisputably bimoraic. Although in non-final position, unstressed open syllables are somewhat longer 
(1)
(H) $\mathrm{H}$
$\left[[\text { telefone }]_{\mathrm{PWd}}\right]_{\mathrm{PPh}}$ téléphoner 'to telephone'

\author{
(H) $\mathrm{H}$ \\ 1 \\ $\left.[\text { lə [telefon }]_{\mathrm{PWd}}\right]_{\mathrm{PPh}}$ le téléphone 'the telephone'
}

In short, while the two accents in French fulfil a similar prosodic function as domain-edge markers, it is also clear that they are fundamentally different in nature, and any formal characterisation of the system will need to take account of this. Before turning to the analysis we propose, we outline our assumptions about prosodic structure.

\title{
2.2. Prosodic structure
}

A partial prosodic hierarchy, hypothesised to be universal, is given in (2) (Selkirk 1984, 1986, McCarthy and Prince 1986, Nespor and Vogel 1986).

(2) Phonological Phrase (PPh)

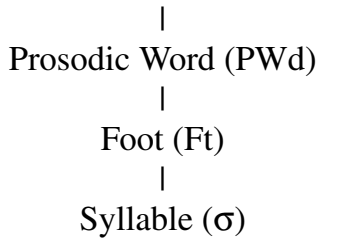

Early work in prosodic phonology assumed that the organisation of material into prosodic constituency must respect the Strict Layer Hypothesis (SLH) (e.g., Selkirk 1984, Nespor and Vogel 1986), where each constituent is strictly dominated by the immediately higher category, as per (2). More recently, researchers have recognised that the SLH is untenable as an inviolable whole. Selkirk (1996), for example, has proposed that the SLH be decomposed into four optimality-theoretic constraints, as in (3).

in duration in French (mean ratio French to English is 1:0.87), final stressed open syllables are considerably longer in English than in French (mean ratio 1:1.36) and the within language ratio for final stressed open syllables to non-final unstressed open syllables is 1:2.78 for English but only 1:1.79 for French. (The ratios for closed syllables are similar to those of open syllables. All ratios are based on the values provided in Delattre 1966: 186.) Thus, while both languages exhibit a phonetic final lengthening effect, only for English is there compelling evidence that final stressed syllables are bimoraic. Further evidence that final lengthening does not involve the addition of a mora in adult French is provided in section 5.1.2 when Clara's outputs are examined. 
(3) Constraints on prosodic domination (Selkirk 1996: 190):
a. LAYEREDNESS:
No $\mathrm{C}^{\mathrm{i}}$ dominates a $\mathrm{C}^{\mathrm{j}}, \mathrm{j}>\mathrm{i}$
(e.g., «No $\sigma$ dominates a Ft»)
b. HEADEDNESS:
Any $\mathrm{C}^{\mathrm{i}}$ must dominate a $\mathrm{C}^{\mathrm{i}-1}\left(\right.$ except if $\left.\mathrm{C}^{\mathrm{i}}=\sigma\right)$
(e.g., «A PWd must dominate a Ft»)
c. Exhaustivity: No $\mathrm{C}^{\mathrm{i}}$ immediately dominates a constituent $\mathrm{C}^{\mathrm{j}}, \mathrm{j}<\mathrm{i}-1$
(e.g., «No PWd immediately dominates a $\sigma »$ )
d. Nonrecursivity: No $\mathrm{C}^{\mathrm{i}}$ dominates $\mathrm{C}^{\mathrm{j}}, \mathrm{j}=\mathrm{i}$
(e.g., «No Ft dominates a Ft»)

The constraints in (3a-b) are universally inviolable; that is, domination relations in the prosodic hierarchy are non-commutable (LAYEREDNESS), and every constituent must dominate at least one constituent of the immediately inferior category (HEADEDNESS). If the prosodic hierarchy is universal and if all structures must respect HEADEDNESS, then each phrase in French must contain at least one prosodic word, and each prosodic word must contain at least one foot. Drawing on evidence from Jun and Fougeron (2000) and Post (2003), we will show that there is clear evidence for the PWd level in French. We will suggest further that the initial high tone denotes the presence of a trochaic foot at the left edge of the PWd, while final lengthening denotes an iambic foot at the right edge of the $\mathrm{PPh}$. Before turning to the details, we first consider the prosodification of functional material.

In contrast to (3a-b), the constraints in (3c-d) are violable; indeed, they are frequently violated in constructions containing function words and inflectional morphology. There are a number of options for the prosodification of functional material, depending on both morpho-syntactic and phonological criteria. Here, we consider only the prosodification of morphologically-free functional items. As (4) shows, in the spirit of Selkirk (1996), we assume that in the unmarked case, such items are prosodified as free clitics; they link directly to the PPh, outside the PWd of the lex on which they depend.

(4) Free clitic (Selkirk 1996: 188):

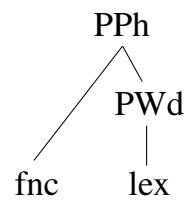

Although this representation comes at some cost as concerns strict layering (EXHAust(PPh) (3c) is violated), the benefit to the learner of a structure like this, where functional material is organised outside the PWd which contains lex, is that the syntactic and phonological representations are isomorphic. Accordingly, learners can use their knowledge of the functional-lexical split in syntax to bootstrap 
into the prosodic representation, or they can use their understanding of differences in the phonological properties of functional versus lexical material to bootstrap into the syntactic representation. ${ }^{3}$ In French, morphologically-free functional items which precede their host such as determiners, prepositions, subject clitics, and preverbal object clitics are prosodified as free clitics (Buckley 2004; see also Cardoso 2003 on closely-related Picard). Indeed, there is no phonological evidence (stress, segmental phenomena) that would lead learners to stray away from this analysis. ${ }^{4}$ In section 6, we will show that this position finds support in Clara's grammar; it is thereby consistent with the view of an elaborated prosodic hierarchy (foot-PWd$\mathrm{PPh}$ ) for child French.

\subsection{Analysis}

In section 2.1, we summarised the debate concerning the status of stress in (Québec) French. Some have assumed that French has no feet; others maintain that it does have feet despite seeming to violate well-attested generalisations governing foot structure. As the prosodic hierarchy - including the foot projection - is hypothesised to hold universally (section 2.2), in the following lines, we will sketch an account of French stress which is largely consistent with the organisation of constituents in this hierarchy. We will then turn our attention to Clara's early outputs which, we will argue, are consistent with this approach.

We saw in section 2.1 that prominence in French is characterised by both an initial and final accent. Initial prominence is indicated by pitch, while the major perceptual cue for final accent is length. Cross-linguistic research reveals that

3. The position taken here is the inverse of that where functional material is initially prosodified internal to the PWd and is moved outside of this domain in the course of acquisition (see Lleó 1997, 2003 and Demuth 2001 for discussion consistent with this view). If functional material were initially prosodified internal to the PWd, we would expect parallel treatment of fnctlex and lex strings which are the same length and have the same stress profile, for example $(ð ə)_{\text {fnc }}+(\text { 'tejbəl })_{\text {lex }}$ 'the table' and (prtejtow) lex 'potato' in English. As we will show in section 6, Clara's grammar does not treat fnc+lex and lex strings in the same fashion which is consistent with the view that leftedge fnc is prosodified outside of the PWd which defines lex.

4. There is one fact which may lead learners to posit that fnc is PWd-internal. Since French permits subminimal words, it is conceivable that the determiner in phrases like [lo le] le lait 'the milk' would be organised internal to the foot and PWd to respect foot binarity. The fact that determiners are almost always required in French is consistent with such an analysis; they could be obligatory before monosyllabic nouns for prosodic reasons and this pattern would then be generalised to nouns of all shapes on morphosyntactic grounds. There is some data in the literature which is compatible with this position. Veneziano and Sinclair (2000) and Tremblay (in press) report a higher incidence of putative function words being produced before monosyllabic lex than before longer lex for the French children they examine; if foot binarity places a lower bound on early outputs, these findings are consistent with these children having arrived at a PWd-internal analysis for fnc (note, however, that Veneziano and Sinclair interpret this asymmetry as support for the view that the putative function words are instead fillers). We do not consider this option further for two reasons. One, in the adult grammar, if function words were organised within the lowest PWd, we would incorrectly expect them to be candidates for left-edge stress (section 2.3). Two, Clara shows evidence of linking fnc directly to the PPh, regardless of the length of the following lexical word. 
trochaic systems tend to be characterised by alternations in pitch and intensity, while iambic systems are marked by alternations in length (Hayes 1995). It would appear, then, that French is a language that has both iambic and trochaic feet. In parametric approaches to stress, it is difficult to formally express a system with both iambs and trochees. In OT, however, where a single constraint can take more than one argument, this scenario is predicted to occur, even if it is rare; that is, there should be some languages where both FoOTFORM(Trochaic) and FoOTFORM(Iambic) are highly ranked. ${ }^{5}$ A conflict will, of course, arise when a language strives to build different types of feet at the same time. We suggest that in French, such a conflict is largely averted as exactly one foot of each type is aligned with opposite edges of the relevant domain. When a conflict does arise, the rightaligned iambic foot takes priority (see below).

To formally express the view that the initial high tone marks the left edge of a trochee while the final accent denotes the right edge of an iamb, we propose the alignment constraints in (5). Since alignment constraints can take any prosodic constituents as arguments, AlignIAmB (5a) can align a right-headed foot with the right edge of the PPh without running afoul of HEADEDNESS (3b) or the organisation of constituents in the prosodic hierarchy (2). Importantly, however, we will demonstrate that there is a role for PWds in the assignment of stress in QF as well, as revealed by (5b) which aligns a left-headed foot with the left edge of the PWd.

\section{a. Final accent:}

AlignIamb: Align (Iamb, R,PPh,R): Align the right edge of every rightheaded foot with the right edge of some $\mathrm{PPh}$

b. Initial accent:

AlignTroch: Align (Troch,L,PWd,L): Align the left edge of every leftheaded foot with the left edge of some PWd

In order for the patterns discussed in section 2.1 to be selected as optimal, AlignIamb must dominate AlignTroch. First, recall that the initial $\mathrm{H}$ tone, which marks the trochaic pattern, is optional, while final lengthening, which reflects the iambic pattern, is always present. Second, the dominance of ALIGNIAMB is revealed in examples where the only PWd in a PPh is bisyllabic. In constructions of this type, AlignIAMB is satisfied at the expense of ALIGNTROCH; see $\left[\mathrm{l}\left[(\text { stilo })_{\mathrm{Ft}}\right]_{\mathrm{PWd}}\right]_{\mathrm{PPh}}$ in (6a). (Both alignment constraints could be satisfied by the alternative $\left[\mathrm{l}\left[(, \mathrm{sti})_{\mathrm{Ft}}(\mathrm{lo})_{\mathrm{Ft}}\right]_{\mathrm{PWd}}\right]_{\mathrm{PPh}}$, a parse which violates *CLASH (no stressed syllables are adjacent) as well as FOOTBINARITY (feet are binary, $\sigma \sigma$ or $\mu \mu$ ). Many speakers of QF do permit parses of this type, although the well-formedness of such parses

5. Languages which appear to have both types of feet have been discussed in the literature; see Gordon (2002) on several languages which have both word-initial and word-final stress, e.g. Armenian and Udihe (he classifies Canadian French in this way as well). See also McCarthy and Prince (1990) on broken plurals in Arabic which follow an iambic pattern whereas the stress system is trochaic, and van de Vijver (1998) on Tiriyó Carib where the stress pattern looks to be iambic except in bisyllabic words where it is trochaic. 
depends in large part on the quality of the vowel in the penultimate syllable.) Turning to (6b), both alignment constraints can readily be satisfied when the PPh contains a single PWd of three or more syllables.

(6)

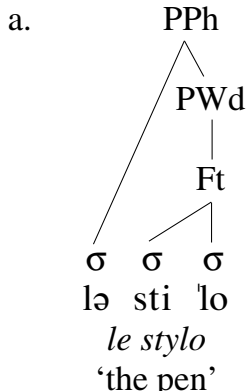

'the pen'

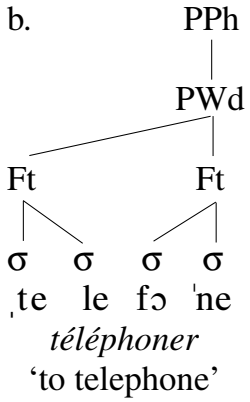

Finally, the structure in (6c) reveals one of the reasons why the argument for the left alignment constraint is the PWd rather than the PPh: left-edge functional material never appears with high tone; it is the first lexical syllable that hosts the initial accent, not the functional material that precedes it (Jun and Fougeron 2000). This is consistent with the view that function words are organised in French as free clitics (4). As mentioned in note 4, if function words were instead within the lowest PWd, we would expect them to be candidates for left-edge stress. The formulation of the AlignTROCH constraint, in combination with the structure in (4), enables this stress pattern to be captured while also reflecting the syntactic constituency.

The second reason why the argument for left alignment is the PWd stems from the results of a study conducted by Post (2003). Post set out to examine the conditions governing variability of stress marking in European French. Using the location of pitch accent as a diagnostic of phrasing, she found that there is variation in what may comprise a PPh. A PPh is minimally composed of one lexical word with its associated function words, but syntactically-dependent units consisting of more than one PWd, such as noun-adjective pairs, may also be parsed as one PPh. Examples of this optionality in phrasing are shown in (7). While the same sequence may be prosodified in a number of ways, each $\mathrm{PPh}$ is subject to the constraints provided in (5). Thus, the option in (7c) where vergers is parsed as trochaic rather than iambic is illicit as it incurs a fatal violation of highly-ranked ALIGNIAMB.

(7) a. [ les [, vergers $\left.]_{\mathrm{PWd}}[\text { 'verts }]_{\mathrm{PWd}}\right]_{\mathrm{PPh}}$ 'the green orchards' the orchards green

b. [les [vergers $\left.\left.]_{\mathrm{PWd}}\right]_{\mathrm{PPh}}[\text { ['verts }]_{\mathrm{PWd}}\right]_{\mathrm{PPh}}$

c. $\left.\left.*[\text { les ['vergers }]_{\mathrm{PWd}}\right]_{\mathrm{PPh}}[\text { ['verts }]_{\mathrm{PWd}}\right]_{\mathrm{PPh}}$ 
In short, while the domain of primary stress assignment in French is the PPh, prosodic structure internal to the $\mathrm{PPh}$, in particular PWd-parsing, is also relevant. This view is consistent with the prosodic hierarchy provided in (2).

\subsection{The challenge for the learner}

The preceding sections have revealed that the facts of French stress are complex. Indeed, the starting point of the debate on how to best capture the system is not what kind of feet French has, but, more fundamentally, whether the language has a foot projection at all. While we have offered a preliminary analysis which makes reference to the various levels of the prosodic hierarchy - including the foot - the fact remains that the system is complex on several dimensions: the presence of a tonal contour, the specifics of which may suggest to the child that the language is not a stress language; the presence of different types of feet at the left and right edges of higher prosodic domains, with different phonetic cues to foot-headedness and different domains for alignment; the observation that the trochaic foot can appear optionally; the alignment of the rightmost foot with the edge of the PPh rather than the PWd; and finally, the existence of rampant violations of word minimality.

In spite of the complexity of the system, we will argue below that Clara's grammar does provide early knowledge of the foot in French. Indeed, we will show that at the earliest stages in development, her grammar respects constraints on prosodic well-formedness which are not necessarily respected in the target grammar.

\section{Earlier evidence for the foot in child QF}

In order to provide a context for an investigation of Clara's prosodic development, we begin by reviewing some of the previous literature which discusses the status of the foot in the acquisition of French. We will demonstrate that, to date, the evidence available for or against the (binary) foot is not conclusive.

We begin with Archibald (1996) and Archibald and Carson (2000). The general research question which these papers seek to address is whether children show an early trochaic bias, as initially proposed by Allen and Hawkins (1978), or whether the evidence for trochees over iambs in the languages studied thus far is an effect of the ambient input. Archibald (1996) observes that final lengthening is robustly present in adult QF outputs. Given the observation mentioned in section 2.3 that the principal cue to stress in iambic languages is length rather than pitch, he concludes that lengthening in the ambient language is a strong enough signal for learners to determine that QF is iambic, even if there may be an initial trochaic bias. The latter position is supported by his examination of the outputs from one child aged $2 ; 4$ where final lengthening was widely attested.

The link that Archibald (1996) makes between the presence of lengthening and the building of iambs is not definitive, however, as the lengthening that is observed may simply be phrase-final lengthening (see Allen 1983 and Hallé, Boysson-Bardies and Vihman 1991 on final lengthening in child French). Thus, the findings from this paper are not conclusive as regards the status of the foot in French. Indeed, in 
the later paper by Archibald and Carson (2000), the authors arrive at the same conclusion. In an examination of truncations from three QF children (age range 1;3 to $1 ; 10$ ), they observe that the children overwhelmingly truncate to monosyllables (where the final accented syllable is retained). That is, they do not truncate to create bisyllabic iambs.

The results in Paradis (2001) (see also Paradis, Petitclerc and Genesee 1997) are more suggestive of the presence of a binary iambic foot in early French. Paradis reports on the performance of QF children (age range 2;4 to 3;0) on a nonsense word repetition task with stimuli that are four syllables long. She finds that children overwhelmingly retain the final syllable in truncation (92\%); the preference for retention of other syllables decreases relative to their position in the target string: $\sigma_{3}$ in the string $\sigma_{1} \sigma_{2} \sigma_{3} \sigma_{4}$ is retained over $\sigma_{2}$ and $\sigma_{1}\left(71 \%\right.$ for $\left.\sigma_{3}\right)$ but the retention of $\sigma_{2}$ over $\sigma_{1}$ (45\% vs. $37 \%$ respectively) is not significant. She suggests that the preferred retention of the syllable adjacent to the stressed syllable over those further away is evidence of an iambic template to which material from longer forms is mapped. ${ }^{6}$ However, we are not told what proportion of truncations were to bisyllabic as opposed to monosyllabic and trisyllabic, nor what proportion of forms were not truncated at all. We are only told that the average output length in syllables is 2.77 which suggests that a large number of three-syllable outputs were produced, as well as perhaps some monosyllabic outputs. It is thus impossible to tell for certain the role that foot binarity might be playing in these children's grammars.

Demuth and Johnson (2003) examine the role of the foot in the outputs of Suzanne, a learner of Parisian French, from 1;1 to 1;8 (data from Deville 1891). They observe that while Suzanne usually truncates trisyllabic targets to bisyllabic from when they are first attempted at 1;4 until 1;7, she happily tolerates CV outputs. $\mathrm{CV}$ targets are apparently not augmented and, surprisingly, bisyllabic targets are truncated to CV from 1;5-1;8 (e.g., [3yp̃̃] $\rightarrow$ [po] jupon 'petticoat'), even though Suzanne had earlier produced them as reduplicated CVCV (e.g., [ Japo] $\rightarrow$ [popo] chapeau 'hat'). Demuth and Johnson attribute truncation to CV to a combination of Suzanne's impoverished consonant inventory and the frequency of subminimal outputs in the ambient language: when Suzanne encounters an illicit consonant in an unstressed syllable, she resolves to repair the problem through deletion of the entire syllable (see also Boysson-Bardies 1996).

From the observations about truncation and the apparent lack of augmentation, it would appear that the binary foot places an upper bound on Suzanne's outputs but not a lower bound. However, there are few examples of trisyllabic forms attempted before 1;7 and so the upper bound effects must be interpreted with caution. In addition, at 1;5, there are some cases of truncation of trisyllabic forms to subminimal CV. Truncation of bisyllabic targets to CV is robustly attested, although as Demuth and Johnson point out, Deville's transcriptions are orthographic and it is thus impossible to be certain that Suzanne's CV outputs were not augmented through

6. Note that this could instead be attributed to high-ranking CONTIGUITY which, in combination with other constraints, will favour retention of material that is adjacent to the final syllable in the input. 
vowel lengthening. In short, it is difficult to determine the status of the foot in Suzanne's grammar.

We turn finally to Rose who has undertaken a comprehensive investigation of many aspects of Clara's development, the same child that we focus on in this paper. Rose (2000) argues that the binary foot plays a role in Clara's grammar in circumscribing the domain of consonant harmony $(\mathrm{CH})$ (he does not focus on stress). Based on additional data from Clara, Rose later modifies this analysis in collaborative work with dos Santos. Rose and dos Santos (2004) adopt an unbounded foot for (adult) French, where all syllables in the phrase are internal to this constituent, and they propose that this is the domain for $\mathrm{CH}$ in Clara's grammar. We see two problems with this analysis. One, this view of the foot is not compatible with a foot-based analysis of left-edge prominence in adult French (sections 2.1 and 2.3). Two, the analysis does not account for examples where $\mathrm{CH}$ crosses foot boundaries (see (9b,d) below). As we will show below, an analysis of the $\mathrm{CH}$ data which does not make reference to the foot at all is possible. Thus, as in the other studies of French acquisition that we have discussed, there does not appear to be strong evidence for the foot, binary or unbounded, from Clara's $\mathrm{CH}$ patterns.

Rose's (2000) analysis of CH in Clara's outputs is motivated by the observation that harmony applies from $\mathrm{C}_{2}$ to $\mathrm{C}_{1}$ in $\mathrm{C}_{1} \mathrm{VC}_{2} \mathrm{~V}(\mathrm{C})$ words (e.g., [də'bu] $\rightarrow$ [ba'bu:] debout 'standing'), but not from $\mathrm{C}_{2}$ to $\mathrm{C}_{1}$ in $\mathrm{C}_{1} \mathrm{VC}_{2}$ words (e.g., [dam] $\rightarrow$ [dam], *[bam] dame 'lady'). As Rose points out, if French builds a single iamb at the right edge of the PPh and word-final consonants are onsets of empty-headed syllables (section 5.1.3 below), the rightmost consonant in words like [dam] cannot be located in the head of the foot; see (8a). The foot must instead be built one syllable in from the right edge with the final impoverished syllable ([mØ]) linking directly to the $\mathrm{PWd}$. The absence of $\mathrm{CH}$ follows directly from this representation, as the triggering consonant is outside the domain in which the process operates. In words like [də'bu], by contrast, the rightmost consonant is inside the foot and can thereby trigger $\mathrm{CH}$ to its left, yielding [ba'bu:]; see (8b).

a.

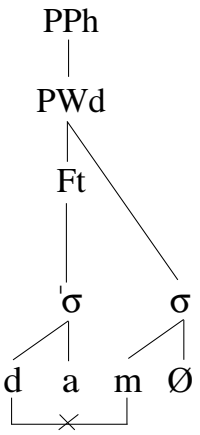

b.

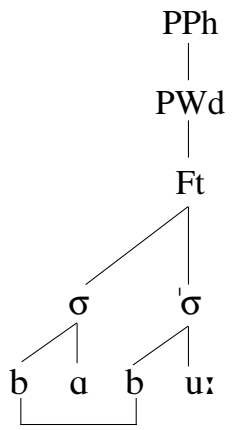

Further data examined by Rose and dos Santos (2004) reveal that once leftedge clitics emerge (at Stage 3; see Table 1 below), the domain of $\mathrm{CH}$ is larger than the binary foot: clitics (or perhaps fillers; see section 6) fall within its scope. 
Focussing on Velar $\mathrm{CH}$, the examples they provide are in (9a-b). We have provided additional Labial $\mathrm{CH}$ examples in (9c-f); the examples in (9e-f) show that trisyllabic lex and phrases containing two PWds can also be targeted. (Note that $\mathrm{CH}$ applies optionally in the longer domains in (9).)

Target:

Velar $\mathrm{CH}$ :
a. [dzyka'ka]
b. [sedzyka'ka]

Labial CH: c. [apapa]

d. [ãla'p̃̃]

e. [otobys]

f. [gвоs'basb]
Clara's output:

[geke'kæ]

['kegjoge'kæ]

[bapæ'pa]

[pesbe'be]

[bybybuç]

[be'bæb?]
Orthography:

du caca

c'est du caca

à papa

un lapin

autobus

grosse barbe
Gloss:

'the poop' 4

'it's the poop' 4

'to dad' 3

'a rabbit' 4

'bus' 5

'big beard' 5

The structures in (10) reveal that an alternative account to that where the unbounded foot constitutes the domain of $\mathrm{CH}$ is possible, one which does not require a foot projection at all. $\mathrm{CH}$ is initiated from the accented syllable and spreads leftward within the $\mathrm{PPh}^{7}$ In the structures provided, the accented syllable is underlined, rather than being marked with the IPA diacritic for stress, to emphasise the fact that, under the analysis being entertained, this syllable is phonetically prominent but is not organised as the head of a foot. The prosodic constituent above the syllable node is labelled PPh to leave open the question as to whether or not the PWd (in contrast to the lexical word) can be motivated for French (see, e.g., Jun and Fougeron 2000 who propose that the lowest prosodic constituent available in French is the Accentual Phrase which closely corresponds to the PPh).

(10)

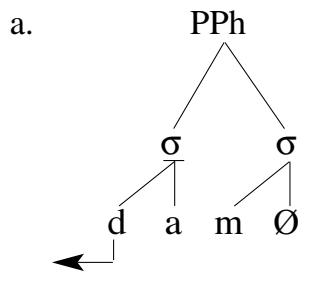

b.

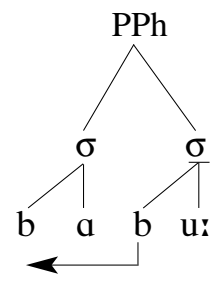

c.

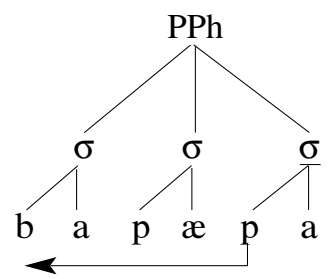

In sum, if leftward directionality is explicitly built into the analysis, the need for the foot, as a binary or unbounded constituent, is not necessary to correctly cir-

7. The representation in (10a) assumes that, in consonant-final words, the final consonant is outside the syllable which bears the accent, parallel to (8a). However, an analysis which is agnostic to the syllabification status of this consonant is possible as well, one which appeals to positional faithfulness to the onset of an accented syllable; a constraint of this type will ensure that the onset does not lose its place at the expense of the place of the final consonant spreading leftward, e.g. [dam] $\rightarrow$ *[bam] (see Pater and Werle 2003). 
cumscribe the domain of $\mathrm{CH}$. The evidence for the foot in Clara's grammar is thus inconclusive at this point.

We turn now to an investigation of Clara's stress patterns, where we will further examine the status of the foot in her grammar. We begin by providing more background information on the data collection and stages in development.

\section{Overview of data source and stages in development}

The dialect of French that Clara is learning is middle-class QF as spoken in Québec City. Data were collected from the onset of word production, at 1;00,28, until $2 ; 07,19$. The sample involves, for the most part, spontaneous production data, collected while the child played with toys or looked at picture books. The data were audio-recorded by Clara's mother and were phonetically transcribed and checked by two native speakers of Québec French (see Rose 2000 for further details).

As we are interested in evidence for or against the foot from the earliest point in Clara's development, the focus of the present paper is on the first 20 data collection sessions, from $1 ; 00,28$ to $1 ; 10,10$. Table 1 shows that the data from this window of time have been divided into five stages on the basis of changes in the development of Clara's grammar that are related to the topics under investigation; these will be elaborated on below at appropriate points in the paper.

In the following sections, a number of arguments will be presented in favour of the position that Clara has built a binary iambic foot at the right edge of the $\mathrm{PPh}$ : word minimality effects, the distribution of final lengthening, the emergence of word-final consonants, and the organisation of functional material into prosodic structure. The optional initial trochee will be discussed briefly as well.

Table 1. Stages in development.

\begin{tabular}{lllll}
\hline Stage & Sessions & Age range & No of phrases & Major characteristics of stage \\
\hline 1 & $1-3$ & $1 ; 00,28-1 ; 02,18$ & 21 & $\begin{array}{l}\text { 2-syll lexical items attempted } \\
\text { (names and adverbs only) }\end{array}$ \\
\hline 2 & $4-7$ & $1 ; 03,07-1 ; 03,23$ & 77 & $\begin{array}{l}\text { 1-syll lexical items attempted; } \\
\text { lexical items which require } \\
\text { left-edge functional material } \\
\text { attempted }\end{array}$ \\
\hline 3 & $8-11$ & $1 ; 04,07-1 ; 04,17$ & 161 & $\begin{array}{l}\text { Emergence of left-edge } \\
\text { functional material and phrases } \\
\text { of more than one PWd }\end{array}$ \\
\hline 4 & $12-14$ & $1 ; 05,05-1 ; 06,22$ & 144 & $\begin{array}{l}\text { 3-syll lexical items begin to be } \\
\text { produced as target-like; } \\
\text { significant increase in } \\
\text { subminimal outputs }\end{array}$ \\
\hline 5 & & & & $\begin{array}{l}\text { Word-final consonants } \\
\text { (other than [b]) emerge }\end{array}$ \\
\hline
\end{tabular}




\section{Word minimality in Clara's grammar}

In the literature on first language acquisition, it has commonly been observed that after the stage in development during which outputs are largely restricted to CV words, children enter the «minimal word» stage, where outputs are minimally - and maximally - one binary foot (e.g., Allen and Hawkins 1978, Gerken 1994, Fikkert 1994, Wijnen, Krikhaar and den Os 1994, Demuth and Fee 1995). As we will argue below, word minimality effects are observed in Clara's outputs as well; constraints responsible for deriving such effects conspire to place both a lower bound and an upper bound on the shapes of her outputs at early stages in development. We will address each in turn.

\subsection{Lower bound effects}

In trochaic languages such as English, Dutch and German, early grammars show widespread truncation of forms that cannot be parsed as a single foot. ${ }^{8}$ The stressed syllable and some following syllable are retained, but in ' $\sigma_{1} \sigma_{2} \sigma_{3}$-shaped words, there is some disagreement as to whether $\sigma_{2}$ or $\sigma_{3}$ survives (Gerken 1994 vs. Echols and Newport 1992, Kehoe and Stoel-Gammon 1997) or whether the two patterns are equally favoured (Wijnen, Krikhaar and den Os 1994). Once morphological and segmental considerations (on relative sonority and place markedness) are factored in, the evidence for $\sigma_{3}$ over $\sigma_{2}$ is particularly strong (Pater 1997) and so, in the discussion below, we will refer to this pattern as preservation of stressed and rightmost.

In Pater's analysis, where OT constraints regulate the shapes of children's outputs, reduction to the minimal word is captured through satisfaction of FootBinarity, Exhaust(PWd) (see (3c) $)^{9}$ and AlignFoot (Align (Ft, R, PWd, $\mathrm{R})$ : align the right edge of every foot with the right edge of the PWd), at the expense of MAX-IO (every segment in the input has a correspondent in the output). ${ }^{10}$ Preservation of stressed and rightmost is captured through undominated STRESSFAITH (an input stressed element must have as its output correspondent a stressed element) and ANCHORRIGHT-IO (elements at the right edge of the input word and the output word stand in correspondence). ${ }^{11}$ This is demonstrated in the tableau in (11)

8. Interestingly, widespread truncation is not always observed in trochaic languages; see Demuth (2001) and Lleó (2002) on Spanish where truncated outputs occur alongside outputs with an initial unfooted syllable. We will see in section 5.2 that the same holds true of Clara's grammar at Stages 4 and 5 .

9. Pater uses the more common ParseSyllable (syllables are parsed into feet) in place of ExhAust(PWd). We have used the latter as we make reference to other constraints from this family as well.

10. Pater uses AlignFoot-Left rather than AlignFoot-Right as we have used. Both constraints make the same prediction when outputs are exactly one foot long. We have chosen to use the latter because in target English and French, the foot parse proceeds from right to left.

11. To ensure that ANCHORRIGHT-IO is not violated when final consonants are deleted, a very common process in child language, we interpret «elements» to stand for syllables, not segments; see Curtin (2001) for an alternative formulation of this constraint which is expressed in terms of the phonetic prominence of final syllables. 
where the optimal output, ['simən], is the only candidate to satisfy all of the highranking constraints under consideration.

\section{(11) Truncation in child English}

\begin{tabular}{|c|c|c|c|c|c|c|}
\hline $\begin{array}{l}\text { ‘cínnamon' } \\
\text { (Julia 1;11,15) }\end{array}$ & FTBIN & $\begin{array}{c}\text { EXH } \\
(\mathrm{PWd})\end{array}$ & $\begin{array}{l}\text { ALIGN } \\
\text { FoOT }\end{array}$ & $\begin{array}{l}\text { STRESS } \\
\text { FAITH }\end{array}$ & $\begin{array}{l}\text { ANCHOR } \\
\text { RIGHT }\end{array}$ & MAX \\
\hline a. $\left[(\sin ə)_{\mathrm{Ft}} \mathrm{m} \partial n\right]_{\mathrm{PWd}}$ & & $* !$ & & & & \\
\hline 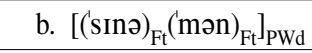 & & & $* !$ & & & \\
\hline c. $\left[(' \mathrm{sI})_{\mathrm{Ft}}\right]_{\mathrm{PWd}}$ & $* !$ & & & & $*$ & $* * * * *$ \\
\hline d. $\left[(\sin \theta)_{\mathrm{Ft}}\right]_{\mathrm{PWd}}$ & & & & & $* !$ & $* * *$ \\
\hline e. $\left[(\text { 'nəmən })_{\mathrm{Ft}}\right]_{\mathrm{PWd}}$ & & & & $* !$ & & $* *$ \\
\hline 曲f. $\left[(\operatorname{sim} ə n)_{\mathrm{Ft}}\right]_{\mathrm{PWd}}$ & & & & & & $* *$ \\
\hline
\end{tabular}

The hierarchy of constraints in (11) is consistent with a ranking of Markedness > Faith which has commonly been argued to reflect the initial state in development (Demuth 1995, Gnanadesikan 1995/2004, Smolensky 1996, inter alia). We therefore take this ranking as the starting point for French-learning children as well. In the following lines, we will compare the predictions that (11) makes for learners of French, under both of the views that (child) French has and does not have a foot projection. We begin with the latter position.

Recall from section 2.1 that in French, the rightmost syllable with a full-vowelled nucleus in the PWd (or technically $\mathrm{PPh}$ ) is prominent. ${ }^{12}$ This prominence will not be analysed as stress if Clara's grammar has no foot projection, and FTBIN will not factor into the well-formedness of her outputs at all. Turning to STRESSFAITH, if this constraint is conceived of as in Pater, as «preservation of the most acoustically salient syllable» (p. 222; our emphasis), then STRESSFAITH will not be limited to head of foot and it, along with ANCHORRIGHT, will strive toward maintainence of the same syllable in languages with final prominence like French (assuming that final prominence is more salient than the initial high tone which, recall, is realised only optionally). Reduction of all syllables to the left of this syllable should be evident at early stages because of high-ranking EXHAUST(PWd); indeed, with no foot projection, every syllable that survives in the output will incur a violation of this constraint. As a result, there should be no asymmetries in reduction/retention patterns based on the number of syllables in the target word.

This scenario is illustrated in the tableaux in (12) for one- and two-syllable lexical targets respectively (i.e., targets that do not require a proclitic in French).

12. In the interest of direct comparison with English in (11), we will use PWd instead of PPh. Note that all of Clara's phrases are single PWds until Stage 3 (see Table 1) and so there will be no empirical difference between characterising the prosodic category to which the foot must be aligned as the PWd or PPh until this point. 
Phonetically prominent syllables are underlined as in (10) above. (FAITH collapses both MAX-IO and DEP-IO; the latter disfavours epenthesis: every segment in the output has a correspondent in the input.)

(12) Expected outputs with no foot projection

\begin{tabular}{|c|c|c|c|c|c|c|}
\hline a. /gi// Guy (name) & FTBIN & $\begin{array}{c}\text { EXH } \\
(\mathrm{PWd})\end{array}$ & $\begin{array}{l}\text { ALIGN } \\
\text { FoOT }\end{array}$ & $\begin{array}{c}\text { STRESS } \\
\text { FAITH }\end{array}$ & $\begin{array}{c}\text { ANCHOR } \\
\text { RIGHT }\end{array}$ & FAITH \\
\hline 吧i. [qi $]_{\mathrm{PWd}}$ & & $*$ & & & & \\
\hline ii. [əggi $]_{\mathrm{PWd}}$ & & $* * !$ & & & & * \\
\hline iii. $[\mathrm{gii}]_{\mathrm{PWd}}$ & & $*$ & & & & $* !$ \\
\hline b. /osi/ aussi 'also' & FTBIN & $\begin{array}{c}\text { EXH } \\
(\mathrm{PWd})\end{array}$ & $\begin{array}{l}\text { ALIGN } \\
\text { FoOT }\end{array}$ & $\begin{array}{c}\text { STRESS } \\
\text { FAITH }\end{array}$ & $\begin{array}{c}\text { ANCHOR } \\
\text { RIGHT }\end{array}$ & FAITH \\
\hline i. $[\mathrm{os} \underline{\mathrm{si}}]_{\mathrm{PWd}}$ & & $* * !$ & & & & \\
\hline ii. $[\underline{\mathrm{o}}]_{\mathrm{PWd}}$ & & $*$ & & $* !$ & $*$ & $* *$ \\
\hline 1ii. $[\underline{\mathrm{si}}]_{\mathrm{PWd}}$ & & $*$ & & & & $*$ \\
\hline
\end{tabular}

The tableau in (12a) shows that one-syllable targets should not be augmented to two syllables (12a-ii), as an additional violation of ExHAUST(PWd) will ensue. Augmenting the form through vowel lengthening, (12a-iii), ties with the optimal output on EXHAUST(PWd), but it needlessly incurs a violation of FAITH (as well as violating a constraint against long vowels). The tableau in (12b) reveals that EXHAUST(PWd) will also be responsible for ensuring that two-syllable targets are truncated to one syllable. In short, with no foot projection, all outputs at early stages in development are predicted to be truncated to the final prominent syllable, regardless of the number of syllables in the input.

Had the optimal outputs in (12) been footed, they would have violated FTBIN. Accordingly, under the option where the French learner's grammar does have a foot projection, different outputs are predicted to be optimal, as can be seen in the tableaux in (13). To satisfy high-ranking FTBIN, monosyllabic outputs like Guy must be augmented to (C)VCV (13a-ii) or to CVV (13a-iii) (depending on the ranking of other constraints). Similarly, both syllables in bisyllabic forms like aussi must be preserved (13b-i) or, if there is truncation due to other markedness constraints, the surviving vowel must be lengthened.

We will demonstrate below that Clara's outputs are consistent with her grammar having a foot projection, as productions along the lines of the optimal forms in (13) are robustly attested, until Stage 4. 
(13) Expected outputs with foot projection

\begin{tabular}{|c|c|c|c|c|c|c|}
\hline a. /'gi/ Guy (name) & FTBIN & $\begin{array}{c}\text { EXH } \\
(\mathrm{PWd})\end{array}$ & $\begin{array}{l}\text { ALIGN } \\
\text { FoOT }\end{array}$ & $\begin{array}{c}\text { STRESS } \\
\text { FAITH }\end{array}$ & $\begin{array}{l}\text { ANCHOR } \\
\text { RIGHT }\end{array}$ & FAITH \\
\hline i. $\left[(\text { 'gi })_{\mathrm{Ft}}\right]_{\mathrm{PWd}}$ & $* !$ & & & & & \\
\hline 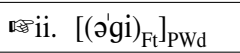 & & & & & & * \\
\hline (fiii. $\left[(\text { gi: })_{\mathrm{Ft}}\right]_{\mathrm{PWd}}$ & & & & & & $*$ \\
\hline b. /o'si/ aussi 'also' & FTBIN & $\begin{array}{c}\text { EXH } \\
(\mathrm{PWd})\end{array}$ & $\begin{array}{l}\text { ALIGN } \\
\text { FOOT }\end{array}$ & $\begin{array}{c}\text { STRESS } \\
\text { FAITH }\end{array}$ & $\begin{array}{l}\text { ANCHOR } \\
\text { RIGHT }\end{array}$ & FAITH \\
\hline \multicolumn{7}{|l|}{ 䟚i. $\left[\left(\text { ossi }_{\mathrm{Ft}}\right]_{\mathrm{PWd}}\right.$} \\
\hline 19i. $\left[(\text { si: })_{\mathrm{Ft}}\right]_{\mathrm{PWd}}$ & & & & & & $* *$ \\
\hline iii. $\left[(\mathrm{o})_{\mathrm{Ft}}\right]_{\mathrm{PWd}}$ & $* !$ & & & * & * & $* *$ \\
\hline iv. $\left[(' \mathrm{si})_{\mathrm{Ft}}\right]_{\mathrm{PWd}}$ & $* !$ & & & & & $*$ \\
\hline
\end{tabular}

\subsubsection{The role of foot binarity}

Tables 2 and 3 summarise the patterns for the lower bound on Clara's words for the five stages under consideration. Importantly, as [в]-final targets virtually always trigger compensatory lengthening in Clara's outputs (Rose 2000, 2002), all stimuli of this shape have been excluded from the counts in Tables 2 and 3, so as not to inadvertently inflate the number of forms which have been augmented for foot structure reasons.

The final column in Table 2 shows that the overall pattern, until Stage 4, is that Clara's outputs for one-syllable lexical targets are infrequently subminimal, consistent with undominated FTBIN.

Table 2. One-syll lexical targets, (A) not requiring and (B) requiring fnc ( $\sigma$ is lexical; $\underline{\sigma}$ is functional).

\begin{tabular}{|c|c|c|c|c|c|c|c|c|c|c|c|c|}
\hline \multirow[b]{2}{*}{ Stage } & \multicolumn{4}{|c|}{ (A) Outputs for $1 \sigma$-lex targets } & \multicolumn{7}{|c|}{ (B) Outputs for $1 \sigma-f n c+1 \sigma$-lex targets } & \multirow{2}{*}{$\begin{array}{c}\text { Total } \\
\text { submin } \\
\text { outputs }\end{array}$} \\
\hline & $\begin{array}{c}\mathrm{N}^{0} \\
\text { attemp }\end{array}$ & $\begin{array}{c}\left(\sigma_{\mu}\right) \\
(\text { submin })\end{array}$ & $\left(\sigma_{\mu \mu}\right)$ & $(\sigma \sigma)$ & $\begin{array}{c}\mathbf{N}^{0} \\
\text { attemp }\end{array}$ & $\begin{array}{c}\left(\sigma_{\mu}\right) \\
(\text { submin })\end{array}$ & $\mid \begin{array}{c}\sigma \\
\sigma\left(\sigma_{\mu}\right) \\
(\operatorname{submin})\end{array}$ & $\left(\sigma_{\mu \mu}\right)$ & $\underline{\sigma}\left(\sigma_{\mu \mu}\right)$ & $(\sigma \sigma)$ & $\underline{\sigma}(\sigma \sigma)$ & \\
\hline 1 & 0 & -- & -- & -- & 0 & -- & -- & -- & -- & -- & -- & 0 \\
\hline 2 & 15 & $\begin{array}{c}2 \\
(13 \%)\end{array}$ & $\begin{array}{c}11 \\
(74 \%)\end{array}$ & $\begin{array}{c}2 \\
(13 \%)\end{array}$ & 1 & 0 & 0 & 0 & 0 & & $0 \%$ & $\begin{array}{c}2 \\
(13 \%)\end{array}$ \\
\hline 3 & 13 & $\begin{array}{c}5 \\
(38 \%)\end{array}$ & $\begin{array}{c}4 \\
(31 \%)\end{array}$ & $\begin{array}{c}4 \\
(31 \%)\end{array}$ & 11 & 1 & \%) 1 & & 5 & 2 & $\%)$ & $\begin{array}{c}7 \\
(29 \%)\end{array}$ \\
\hline 4 & 32 & $\begin{array}{c}19 \\
(60 \%)\end{array}$ & $\begin{array}{c}11 \\
(34 \%)\end{array}$ & $\begin{array}{c}2 \\
(6 \%)\end{array}$ & 29 & 9 & $\left.\right|_{6 \%)} 13$ & 2 & 2 & 0 & ${ }^{3}$ & $\begin{array}{c}41 \\
(67 \%)\end{array}$ \\
\hline 5 & 82 & $\begin{array}{c}58 \\
(71 \%)\end{array}$ & $\begin{array}{c}21 \\
(25 \%)\end{array}$ & $\begin{array}{c}3 \\
(4 \%)\end{array}$ & 107 & 38 & \%) & $\begin{array}{l}7 \\
(1\end{array}$ & $3 \%$ & 5 & $\%$ & $\begin{array}{c}139 \\
(74 \%)\end{array}$ \\
\hline
\end{tabular}


The columns under (A) show the profile for those one-syllable lexical targets which do not require a proclitic. Until Stage 4, these forms are overwhelmingly augmented, primarily through vowel lengthening, $\sigma \rightarrow\left(\sigma_{\mu \mu}\right)_{\mathrm{Ft}}$, but also through the addition of a pretonic syllable, $\sigma \rightarrow(\sigma \sigma)_{\mathrm{Ft}}$ (note that, for each of Stages 2-3 and 5, there is one example of augmentation to three syllables). These outputs are parallel to candidates (iii) and (ii) respectively in tableau (13a). Representative examples of all output patterns are in (14). (Some examples which follow the $\sigma \rightarrow(\sigma \sigma)_{\mathrm{Ft}}$ pattern may surface as such because of constraints on segmental licensing or syllable complexity, a question which we leave to future research.)

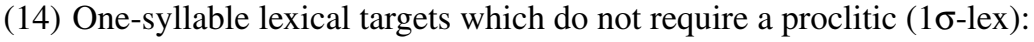

Pattern: Stage: Target: Clara's output: Orthography: Gloss:

\begin{tabular}{|c|c|c|c|c|c|}
\hline \multirow[t]{9}{*}{$\sigma \rightarrow\left(\sigma_{\mu}\right)_{\mathrm{Ft}}$} & 1 & -- & & & \\
\hline & \multirow[t]{2}{*}{2} & [nว̃] & [no] & non & 'no' \\
\hline & & [gi] & [gi] & Guy & (name) \\
\hline & \multirow[t]{2}{*}{3} & [pa] & {$[\mathrm{pa}]$} & pas & 'not' \\
\hline & & [gi] & [gi] & Guy & (name) \\
\hline & \multirow[t]{2}{*}{4} & [ki] & [ki] & qui & 'who' \\
\hline & & [ñ̃] & [no] & non & 'no' \\
\hline & \multirow[t]{2}{*}{5} & [ьво̃ ] & [bœ] & brun & 'brown' \\
\hline & & {$[\mathrm{me}]$} & {$[\mathrm{me}]$} & mets & 'put' (imper) \\
\hline \multirow{9}{*}{$\sigma \rightarrow\left(\sigma_{\mu \mu}\right)_{\mathrm{Ft}}$} & \multirow{3}{*}{2} & -- & & & \\
\hline & & [gi] & [gi:] & Guy & (name) \\
\hline & & [ñ̃] & [nov] & non & 'no' \\
\hline & \multirow[t]{2}{*}{3} & [wi] & [wi:] & oui & 'yes' \\
\hline & & [воZ] & [lu:s] & rose & 'pink' \\
\hline & \multirow[t]{2}{*}{4} & [pa] & [pæ:] & pas & 'not' \\
\hline & & [wi] & [wวi] & oui & 'yes' \\
\hline & \multirow[t]{2}{*}{5} & [sa] & [sa: $]$ & ça & 'that' \\
\hline & & [pa] & [pa:] & pas & 'not' \\
\hline \multirow[t]{9}{*}{$\sigma \rightarrow(\sigma \sigma)_{\mathrm{Ft}}$} & 1 & -- & & & \\
\hline & \multirow[t]{2}{*}{2} & [wi] & [ว่પi] & oui & 'yes' \\
\hline & & [gi] & [jlfilgi:] & Guy & (name) \\
\hline & \multirow[t]{2}{*}{3} & [wi] & [I'ji] & oui & 'yes' \\
\hline & & [gi] & [ว่gi:] & Guy & (name) \\
\hline & \multirow[t]{2}{*}{4} & [nว̃] & [înæ] & non & 'no' \\
\hline & & [la] & [e'je] & là & 'there' \\
\hline & \multirow[t]{2}{*}{5} & [wi] & [ว่vi:] & oui & 'yes' \\
\hline & & [blø] & [əby'ø] & bleu & 'blue' \\
\hline
\end{tabular}

The columns under (B) in Table 2 provide the profile for one-syllable lexical targets which obligatorily require a proclitic in the target grammar (i.e., $1 \sigma-f n c+1 \sigma$ - 
lex). ${ }^{13}$ Recall that such forms are subminimal in adult French, as left-edge function morphemes are organised as free clitics linking directly to the $\mathrm{PPh}$, e.g. [lo $\left.\left[\left(\int \mathrm{a}\right)_{\mathrm{Ft}}\right]_{\mathrm{PWd}}\right]_{\mathrm{PPh}}$ le chat 'the cat' (see section 2.2). Parallel to the generalisations that emerge from the columns under (A), at Stage 4, there is a large increase in the percentage of subminimal forms attested. At Stage 3, strings of this shape are typically augmented through vowel lengthening, regardless of whether or not the clitic is produced by Clara. Examples of all output patterns for $1 \sigma$-fnc $+1 \sigma$-lex targets are provided in (15).

(15) One-syllable lexical targets which obligatorily require a proclitic $(1 \sigma$-fnc + $1 \sigma$-lex):

\begin{tabular}{|c|c|c|c|c|c|}
\hline \multirow{3}{*}{$\begin{array}{l}\text { Pattern: } \\
\underline{\sigma} \sigma \rightarrow\left(\sigma_{\mu}\right)\end{array}$} & Stage: & Target: & Clara's output: & Orthography: & Gloss: \\
\hline & 1 & -- & & & \\
\hline & 2 & -- & & & \\
\hline & 3 & [lə’ne] & [ne] & (le) nez & '(the) nose' \\
\hline & 4 & [lə’pẽ $]$ & [pe] & (le) pain & '(the) bread' \\
\hline & & {$\left[\partial^{\prime} \mid \mathrm{a}\right]$} & [ç)] & (le) chat & '(the) cat' \\
\hline & 5 & 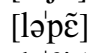 & {$[\mathrm{pe}]$} & (le) pain & '(the) bread' \\
\hline & & {$\left[l_{\partial}^{\prime} \int \mathrm{j} \tilde{\varepsilon}\right]$} & [çјæ] & (le) chien & '(the) dog' \\
\hline
\end{tabular}

\begin{tabular}{|c|c|c|c|c|c|}
\hline \multirow[t]{7}{*}{$\underline{\sigma} \sigma \rightarrow \underline{\sigma}\left(\sigma_{\mu}\right)$} & 1 & \multicolumn{4}{|l|}{--} \\
\hline & 2 & -- & & & \\
\hline & 3 & [ว̃́liv] & [a'ji] & un livre & 'a book' \\
\hline & 4 & [d’'dã] & [de'dp] & de dents & 'of teeth' \\
\hline & & [थें'a] & [ө̆t $\int a$ & un chat & 'a cat' \\
\hline & 5 & [วิ่po] & [ə่'ро] & un pot & 'a pot' \\
\hline & & [lə̀ne] & [l’’nI] & le nez & 'the nose' \\
\hline
\end{tabular}

\begin{tabular}{|c|c|c|c|c|c|}
\hline \multirow{7}{*}{$\underline{\sigma} \sigma \rightarrow\left(\sigma_{\mu \mu}\right)$} & 1 & -- & & & \\
\hline & 2 & -- & & & \\
\hline & 3 & [lo'ne] & [nei] & (le) nez & '(the) $\mathrm{n}$ \\
\hline & 4 & [la'pom] & [bor] & (la) pomme & (the) a \\
\hline & & [leddã] & [dor $]$ & (les) dents & (the) \\
\hline & 5 & [le'dwa] & [dwæ:] & (les) doigts & '(the) $f$ \\
\hline & & [lə’ne] & [ne: ] & (le) nez & '(the) \\
\hline \multirow[t]{4}{*}{$\underline{\sigma} \sigma \rightarrow \underline{\sigma}\left(\sigma_{\mu \mu}\right.$} & 1 & -- & & & \\
\hline & 2 & -- & & & \\
\hline & 3 & {$\left[l^{\prime} \int \mathrm{a}\right]$} & [lə'ta: & le chat & 'the cat' \\
\hline & & [ə'ljõ] & [ə’'la:] & un lion & 'a lion' \\
\hline
\end{tabular}

13. As is evident from the text, the abbreviation $1 \sigma-f n c+1 \sigma$-lex refers to targets where the entire first syllable is functional. Targets like [loto] l'auto 'the car', where lex is vowel-initial, have not been included in this category, as the determiner in this case is organised internal to the PWd of the stem, to satisfy ONSET: [[lo'to $\left.]_{\mathrm{PWd}_{\mathrm{d}}}\right]_{\mathrm{PPh}}$. No forms of the latter type are attempted until Stage 3, and they are not included in any of the counts in Table 2. 


\begin{tabular}{|c|c|c|c|c|c|}
\hline Pattern: & $\begin{array}{l}\text { Stage: } \\
4\end{array}$ & $\begin{array}{l}\text { Target: } \\
\text { [l'liv] } \\
\text { [l'liv] } \\
\text { [cl'sot] } \\
\text { [ dzy'zy] }\end{array}$ & $\begin{array}{l}\text { Clara's output: } \\
\text { [jə'ji: }] \\
\text { [j3'ji: }] \\
\text { [æço:t] } \\
\text { [dy'jy: }]\end{array}$ & $\begin{array}{l}\text { Orthography: } \\
\text { le livre } \\
\text { le livre } \\
\text { elle saute } \\
\text { du jus }\end{array}$ & $\begin{array}{l}\text { Gloss: } \\
\text { 'the book' } \\
\text { 'the book' } \\
\text { 'she jumps' } \\
\text { 'some juice' }\end{array}$ \\
\hline$\delta \rightarrow(\sigma \sigma)$ & $\begin{array}{l}1 \\
2 \\
3\end{array}$ & 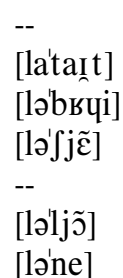 & $\begin{array}{l}\text { [taídda] } \\
\text { [ßu'jii: } \\
\text { [so'le] }\end{array}$ & $\begin{array}{l}\text { (la) tête } \\
\text { (le) bruit } \\
\text { (le) chien }\end{array}$ & $\begin{array}{l}\text { '(the) head' } \\
\text { '(the) noise' } \\
\text { '(the) dog' }\end{array}$ \\
\hline
\end{tabular}

\begin{tabular}{|c|c|c|c|c|}
\hline$\underline{\sigma} \sigma \rightarrow \underline{\sigma}(\sigma \sigma)$ & -- & & & \\
\hline & -- & & & \\
\hline & 3 & & & \\
\hline & [õlliv] & [əja'lir] & un livre & 'a book' \\
\hline & [lə’pen] & [japo'ne] & le peigne & 'the comb' \\
\hline & [ãlljõ] & [Y̌llæujjĕ] & un lion & $\begin{array}{l}\text { 'a lion' } \\
\text { 'a hen' }\end{array}$ \\
\hline
\end{tabular}

Table 3 provides the profile observed in Clara's grammar for two-syllable lexical targets which do not require a proclitic. (Note that this table includes eight outputs at Stages 3-5 labelled $(\sigma \sigma)$ which actually involve augmentation to three syllables, and one output at Stage 4 which involves augmentation to four syllables.)

As can be seen, two-syllable lexical targets are rarely truncated to one syllable, in contrast to the findings of Archibald and Carson (2000). (There are a number of [в]-final forms like [ãkər] encore 'again' and [də.əь] dehors 'outside' which surface as monosyllabic (typically as CVV), perhaps due to other marked-

Table 3. Two-syll lexical targets.

\begin{tabular}{l|c|c|c|c}
\hline Stage & $\begin{array}{c}\mathbf{N}^{\mathbf{0}} \\
\text { attemp }\end{array}$ & $\begin{array}{c}\left(\boldsymbol{\sigma}_{\mu}\right) \\
(\text { submin) }\end{array}$ & $\left(\boldsymbol{\sigma}_{\mu \mu}\right)$ & $(\boldsymbol{\sigma} \boldsymbol{\sigma})$ \\
\hline 1 & 7 & $\begin{array}{c}1 \\
(14 \%)\end{array}$ & 0 & $\begin{array}{c}6 \\
(86 \%)\end{array}$ \\
\hline 2 & 21 & $\begin{array}{c}1 \\
(5 \%)\end{array}$ & 0 & $\begin{array}{c}20 \\
(95 \%)\end{array}$ \\
\hline 3 & 41 & 2 & 2 & 37 \\
$(5 \%)$ & $(5 \%)$ & $(90 \%)$ \\
\hline 4 & 25 & 0 & 1 & 24 \\
$(4 \%)$ & $(96 \%)$ \\
\hline 5 & 76 & $\begin{array}{c}2 \\
(3 \%)\end{array}$ & 0 & $\begin{array}{c}74 \\
(97 \%)\end{array}$ \\
\hline
\end{tabular}


ness constraints, as suggested by the higher proportion of such outputs during Stages 1 and 2; recall, however, that [в]-final targets have not been included in the counts since they trigger compensatory lengthening for reasons independent of foot structure.) In short, outputs which respect FTBIN, along the lines of the optimal candidate in (i) in tableau (13b), are favoured by Clara's grammar. Examples of all output patterns are provided in (16).

(16) Two-syllable lexical targets which do not require a proclitic (2 $\sigma$-lex)

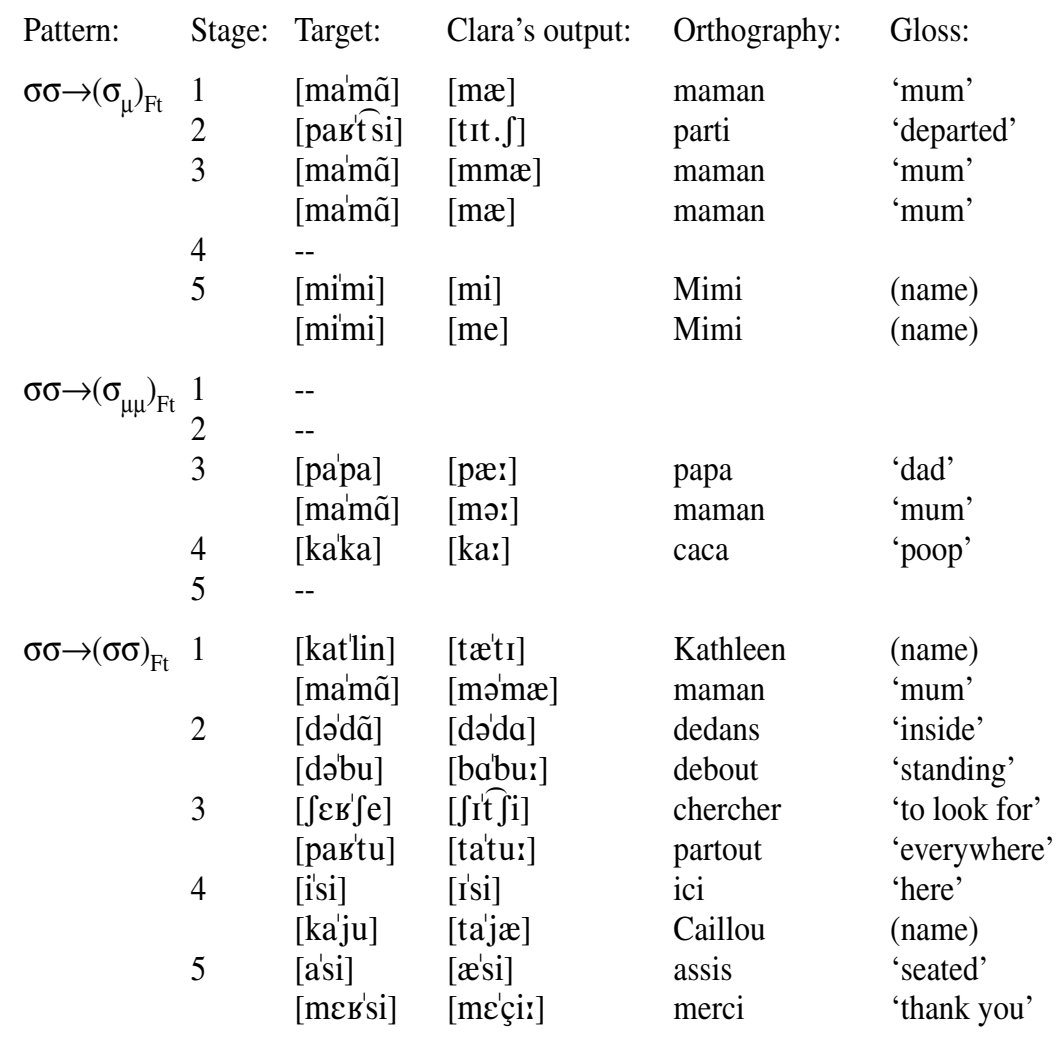

\subsubsection{Augmentation as phrase-final lengthening?}

We have observed that Clara's outputs for one-syllable lexical targets display vowel lengthening to a great extent. That is, the native-speaker transcribers heard these forms as involving significantly greater length than how they would be produced by adult speakers and, thus, they transcribed these forms as CVV. We propose that this difference is formally reflected through the addition of a mora to Clara's early outputs, yielding bimoraic forms for targets of this shape. An important question that must be addressed, however, is whether this lengthening involves augmentation to satisfy FTBIN, as suggested in section 5.1.1, or whether it is instead phrase-final lengthening. In apparent support of the latter position, at the stages when lengthening 
Table 4. Final lengthening in one- and two-syll lexical targets.

\begin{tabular}{|c|c|c|c|c|}
\hline \multirow[b]{2}{*}{ Stage } & \multicolumn{2}{|c|}{$1 \sigma$-lex targets } & \multicolumn{2}{|c|}{$2 \sigma$-lex targets } \\
\hline & $\begin{array}{c}\left(\sigma_{\mu}\right) \\
(\text { submin })\end{array}$ & $\left(\sigma_{\mu \mu}\right)$ & $\left(\sigma \sigma_{\mu}\right)$ & $\left(\sigma \sigma_{\mu \mu}\right)$ \\
\hline $1-3$ & $\begin{array}{c}7 \\
(32 \%)\end{array}$ & $\begin{array}{c}15 \\
(68 \%)\end{array}$ & $\begin{array}{c}47 \\
(75 \%)\end{array}$ & $\begin{array}{c}16 \\
(25 \%)\end{array}$ \\
\hline $4-5$ & $\begin{array}{c}77 \\
(71 \%)\end{array}$ & $\begin{array}{c}32 \\
(29 \%)\end{array}$ & $\begin{array}{c}67 \\
(68 \%)\end{array}$ & $\begin{array}{c}31 \\
(32 \%)\end{array}$ \\
\hline
\end{tabular}

is particularly robust (Stages 1-3), most phrases contain only one PWd; indeed, recall from Table 1 that phrases of more than one PWd are not attempted until Stage 3. If the lengthening exhibited in Table 2 were phrase-final lengthening, it would provide us with no evidence one way or the other about the status of the foot in Clara's grammar.

A comparison of the proportion of lengthening observed in outputs for onesyllable lexical targets, $\left(\sigma_{\mu}\right)$ versus $\left(\sigma_{\mu \mu}\right)$, with the proportion of lengthening observed on the final syllable in outputs for two-syllable lexical targets, $\left(\sigma \sigma_{\mu}\right)$ versus $\left(\sigma \sigma_{\mu \mu}\right)$, reveals that lengthening is indeed motivated by foot well-formedness rather than being a phrase-final effect. If the latter were the source of lengthening, then at early stages in Clara's development, lengthening should be as widely attested for final syllables in two-syllable lexical targets as for one-syllable lexical targets. A glance at Table 4, however, reveals that this is not the case.

At Stages 1-3, the proportion of lengthened to non-lengthened outputs for onesyllable lexical targets is the opposite of that observed for two-syllable lexical targets. This is as expected if, for one-syllable lexical targets, lengthening is motivated by FTBIN. For two-syllable lexical targets, FTBIN is already satisfied by a two-syllable output; thus, there is no motivation for lengthening involving foot well-formedness and widespread lengthening is not expected to occur. At Stages 45 , when the number of subminimal forms in Clara's outputs greatly increases, the proportion of lengthened to non-lengthened outputs for one- and two-syllable lexical targets is expected to be the same; Table 4 shows that this is indeed the case.

\subsubsection{The emergence of word-final consonants}

As mentioned above, Table 2 shows a sharp increase in the number of subminimal outputs for one-syllable lexical targets in the transition from Stage 3 to Stage 4, from an average of $21 \%$ at earlier stages to $71 \%$ at Stages 4 and 5. Why would this be the case? If Clara's patterns of behaviour at earlier stages support the postulation of the foot, it is highly unlikely that this projection is eliminated from her representations at later stages. Not only is this inconsistent with continuity, it is in violation of HEADEDNESS (3b), in this case, the requirement that every PWd contain at least one foot; it is also not consistent with the position we have taken that adult French does indeed support a foot projection (section 2.3).

By Stage 4, when lengthening is less robustly attested in Clara's outputs and her grammar is beginning to tolerate subminimal feet, it would appear that satis- 
faction of the faithfulness constraints that were earlier violated through augmentation is starting to take priority, as in the target grammar. One potentially confounding factor that must be addressed, however, is whether any relationship holds between the sharp increase in subminimal outputs at Stage 4 and Clara's acquisition of word-final consonants. If final consonants were analysed by Clara as moraic codas, vowel lengthening in the case of consonant-final targets would have nothing to do with foot well-formedness, as we have argued, as it would instead be a compensatory lengthening effect; that is, when final consonants are deleted, the preceding vowel would lengthen to license the stranded mora (see Ota 1999 for evidence of compensatory lengthening in child Japanese). When final consonants emerge in Clara's outputs at later stages, the motivation for lengthening would then no longer hold.

In the following lines, we will show that this explanation cannot hold. First, word-final consonants are not robustly attested until Stage 5 (see Table 1), whereas Table 2 shows that the dramatic increase in subminimal outputs begins two months earlier, at the onset of Stage 4; there is also no change in the number of subminimal outputs from Stage 4 to Stage 5. Second, the proportion of vowel-final targets which undergo lengthening is approximately the same as the proportion of consonant-final targets which undergo lengthening at all five stages, thus, even after word-final consonants emerge in outputs. ${ }^{14}$ Finally, there are a number of arguments which support the proposal that word-final consonants (other than [B]; see note 13) in Clara's grammar are syllabified as onsets, not as codas, which makes them ineligible as triggers of compensatory lengthening (see Rose 2000, 2002, Goad 2002). In sum, there is no relationship between the acquisition of word-final consonants and the decrease in subminimal words in Clara's outputs.

In this section, we have argued that there is a lower bound of one binary iamb on Clara's outputs at early stages in development and that this supports the presence of a foot projection in her grammar. We turn now to examine upper bound effects on her early productions.

\subsection{Upper bound effects}

If Clara's grammar at early stages is similar to the grammars of children learning trochaic languages, FTBIN, in combination with undominated AlignFoot and EXHAUST(PWd), will conspire to yield an upper bound on the length of her PWds. That is, outputs should be no longer than one foot, and longer forms should be subject to truncation, as was seen in (11) for English. The tableau in (17) shows how this result is expected for three-syllable lexical words in French. (We will not consider violations of ANCHORRIGHT, so this constraint has been removed from the tableau.)

14. This, however, excludes [в]. As mentioned earlier, word-final [в], almost without exception, triggers compensatory lengthening at Stages 1-5. It is not mastered until 2;03,15, five months after the end of Stage 5, at the same point that word-internal codas are acquired (see Rose 2000, 2002 for details). 
(17) Truncation in child French

\begin{tabular}{|c|c|c|c|c|c|c|}
\hline / difi'sil/ difficile 'difficult' & FTBIN & $\begin{array}{c}\text { EXH } \\
(\mathrm{PWd})\end{array}$ & $\begin{array}{l}\text { ALIGN } \\
\text { FoOT }\end{array}$ & $\begin{array}{c}\text { STRESS } \\
\text { FAITH }\end{array}$ & CONTIG & MAX \\
\hline a. $\left[\operatorname{di}(\text { fi'si })_{\mathrm{Ft}}\right]_{\mathrm{PWd}}$ & & $* !$ & & & & $*$ \\
\hline b. $\left[\left(\mathrm{di}_{\mathrm{Ft}}(\mathrm{fi} i \mathrm{si})_{\mathrm{Ft}}\right]_{\mathrm{PWd}}\right.$ & $* !$ & & * & & & $*$ \\
\hline c. $\left[(\text { di'si })_{\mathrm{Ft}}\right]_{\mathrm{PWd}}$ & & & & & $* !$ & $* * *$ \\
\hline 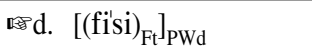 & & & & & & $* * *$ \\
\hline
\end{tabular}

Before we discuss the candidates in (17), some comments on the input are necessary. Recall from section 2.1 that three-syllable targets like difficile optionally have an initial high tone (which we have analysed as secondary stress). Aside from the observation that secondary stress is optional, we have not included this information in the input in (17) because, if Clara were sensitive to the initial $\mathrm{H}$, we would have expected two patterns of behaviour in her outputs which we do not find.

First, as we will see below, three-syllable lexical words are commonly truncated to two syllables in Clara's outputs through Stage 5 (see also Parsons 2005). If the initial $\mathrm{H}$ were particularly salient, we might have expected this syllable to be retained in truncation, yielding forms like [di'si] for difficile. This type of pattern is observed for learners of other languages; for example, Lleó (2002) reports that Spanish-speaking children preserve the initial secondarily-stressed syllable in four-syllable targets (e.g., [mariposa] mariposa 'butterfly' $\rightarrow$ [pa'bota] for José at 1;9.2). Clara's truncated outputs, however, typically show preservation of the syllable adjacent to the final stressed syllable, yielding forms like [fi'si]. Of all truncations of lexical material to bisyllabic for the five stages under consideration where a decision can be made as to which syllable is retained, the penult survives $71 \%$ of the time (cf. Parsons 2005 on Clara; see also Paradis 2001 on other French-speaking children).

Second, to avoid unfooted syllables in early outputs, we might have expected Clara to produce two-foot parses for words like difficile relatively often, yielding forms like [difísi] (or [disfi'si]). Outputs of this shape are unattested until Stage 4 and are relatively infrequent at this point as well (see Table 5 below).

With these considerations in mind, let us return to examine (17). Candidate (a) fatally violates EXHAUST(PWd) but it does not incur a violation of STRESSFAITH if the input is /difi'sil/. The introduction of a second foot in candidate (b) results in a fatal violation of undominated FTBIN as well as ALIGNFoot. Of the two remaining candidates, (d) wins over (c) if another highly-ranked constraint is introduced, I-CoNTIGUITY (the portion of the input standing in correspondence forms a contiguous string); as mentioned in note 6 , I-CONTIG disfavours outputs that violate the integrity of a morpheme through morpheme-internal deletion or epenthesis, as in candidate (c).

Table 5 below shows that Clara's early productions are largely compatible with a grammar like (17) where the constraint ranking yields an upper bound of onefoot on the shape of outputs. As the number of three-syllable lexical targets which 
Table 5. Three-syll lexical targets.

\begin{tabular}{l|c|c|c|c}
\hline Stage & $\begin{array}{c}\mathbf{N}^{\mathbf{2}} \\
\text { attemp }\end{array}$ & $\begin{array}{c}\text { Unfooted } \boldsymbol{\sigma} \\
\boldsymbol{\sigma}(\boldsymbol{\sigma} \boldsymbol{\sigma})\end{array}$ & $\begin{array}{c}\text { Truncation } \\
(\boldsymbol{\sigma} \boldsymbol{\sigma})\end{array}$ & $\begin{array}{c}\mathbf{2 - f t} \\
\text { parses }\end{array}$ \\
\hline 1 & 0 & -- & -- & -- \\
\hline 2 & 1 & 0 & 1 & 0 \\
\hline 3 & 3 & 0 & 3 & 0 \\
\hline 4 & 8 & 1 & $\begin{array}{c}4 \\
(100 \%)\end{array}$ & 3 \\
\hline 5 & 25 & $\begin{array}{c}6 \\
(24 \%)\end{array}$ & $\begin{array}{c}13 \%) \\
(52 \%)\end{array}$ & $\begin{array}{c}6 \\
(24 \%)\end{array}$ \\
\hline
\end{tabular}

do not require a proclitic is quite small in Clara's outputs, the table includes three

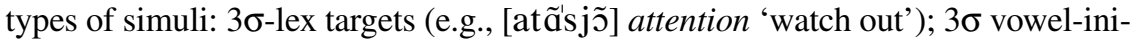
tial lex targets which must be preceded by a single consonant fnc (e.g., [lekу'вœj] l'écureuil 'the squirrel'), as recall from note 12 that, in these cases, fnc is organised internal to the PWd to satisfy ONSET; and $4 \sigma$ targets shaped $1 \sigma$-fnc $+3 \sigma$-lex where the proclitic is not produced (e.g., [pãtal'̃̃] for target [lə pãta'lõ] (le) pantalon '(the) trousers'). Although the numbers are still low, it is important to point out that, across stages, all truncations are to two syllables, supporting the view that a binary foot is what constrains the upper length of Clara's PWds (cf. Archibald and Carson 2000 where truncation was typically to one syllable (section 3)).

The speech samples available suggest that Clara did not attempt any three-syllable words until Stage 2; we take the absence of words of this shape at Stage 1 to be indicative of «selection and avoidance», a commonly-observed phenomenon where children avoid utterances which contain structures not compatible with their grammar (Schwartz and Leonard 1982). While there are only four three-syllable examples attempted at Stages 2 and 3, they all display truncation. The tableau in (17), where EXHAUST(PWd) is undominated, is thus consistent with Clara's behaviour at Stages 1-3.

At Stage 4, the target structure with a PWd-initial unfooted syllable appears, but it is not robustly attested until after Stage 5. At Stages 4 and 5, truncation is still the most common pattern, but the number of cases of truncation is roughly equal to those where all three syllables surface, either with the initial syllable as unfooted or with this syllable forming its own foot. This suggests that the ranking between Exhaust(PWd) and FtBin/AlignFoOT on the one hand and MAX-IO on the other is not stable during this six-month window. Representative examples of the unfooted $\sigma$ and truncation parses are provided in (18); two-foot parses are discussed below. (Note that there are seven examples of stress shift to the penult included in the numbers of unfooted $\sigma$ and truncation parses at Stages 4 and 5 in Table 5, a pattern which is attested in the adult grammar as well (e.g., Ouellet and Thibault 1996). See, for example, Clara's output for écureuil in (18).) 
(18) Three-syllable lexical targets: Unfooted syllables vs. truncation

Pattern: Stage: Target: Clara's output: Orthography: Gloss:

\begin{tabular}{|c|c|c|c|c|c|}
\hline \multirow{6}{*}{$\sigma \sigma \sigma \rightarrow \sigma\left(\sigma^{\prime} \sigma\right)$} & 1 & -- & & & \\
\hline & 2 & -- & & & \\
\hline & 3 & -- & & & \\
\hline & 4 & [еку'ьœj] & [ke'kælæI: & écureuil & 'squirrel' \\
\hline & 5 & [absiko] & [pupæ'ko:] & abricot & 'apricot' \\
\hline & & [deta'e] & [dəta'er] & détacher & 'to untie' \\
\hline \multirow[t]{8}{*}{$\sigma \sigma \sigma \rightarrow(\sigma \delta)$} & 1 & -- & & & \\
\hline & 2 & [ladə่dã] & [la'ðæ: & là-dedans & 'in there' \\
\hline & 3 & [арьi'ko] & [ke'kọ] & apricot & 'apricot' \\
\hline & & [papijõ] & [bə’'ㅎs] & papillon & 'butterfly' \\
\hline & 4 & [pãta'ı̃] & [bo:'je] & pantalon & 'trousers' \\
\hline & & [salo'pet] & {$\left[\mathrm{b}^{\prime} \mathrm{p}^{\mathrm{h}} \mathrm{c}\right]$} & salopette & 'overalls' \\
\hline & 5 & [klemã́t sin] & [mæ'tsi] & clémentine & 'clementine' \\
\hline & & [عskas'go] & [kæ'kọ] & escargot & 'snail' \\
\hline
\end{tabular}

Returning to Table 5, the increase in the number of outputs with two-foot parses should not, in our view, be taken to reflect a strategy to avoid initial unfooted syllables. On the contrary, we believe that it suggests that Clara is becoming aware of the optional initial $\mathrm{H}$ tone in the target language. Exactly how optional phenomena such as this are learned is not well-understood, but we assume that they take more time than obligatory phenomena, as the learner requires more instances to conclude that a particular pattern is robust enough to be formally represented in the grammar. Examples of Clara's two-foot parses are provided in (19). Here, the optional $\mathrm{H}$ tone has been included in the targets.

(19) Three-syllable lexical targets: 2-foot parses

\begin{tabular}{|c|c|c|c|c|c|}
\hline Pattern: & Stage: & Target: & Clara's output: & Orthography & Gloss: \\
\hline \multirow{6}{*}{$\sigma \sigma \sigma \rightarrow(\sigma)(\sigma \sigma)^{15}$} & 1 & -- & & & \\
\hline & 2 & --. & & & \\
\hline & 3 & -- & & & \\
\hline & 4 & [piza'ma] & [mejæ'na] & pyjama & 'pyjamas' \\
\hline & & [piza'ma] & [jøem.3je] & pyjama & 'pyjamas' \\
\hline & 5 & $\begin{array}{l}\text { [klemã̃t sın] } \\
\text { [atấsjõ }]\end{array}$ & $\begin{array}{l}{\left[æ m a t \sin ^{\urcorner}\right]} \\
{\left[\mathfrak{x} \tilde{x} \int \mathrm{j} \tilde{j}\right]}\end{array}$ & $\begin{array}{l}\text { clémentine } \\
\text { attention }\end{array}$ & $\begin{array}{l}\text { 'clementine' } \\
\text { 'watch out' }\end{array}$ \\
\hline
\end{tabular}

15. We have provided the foot parse here as $(\sigma)(\sigma \sigma)$, rather than as $(\sigma \sigma)(\sigma)$. In examples where the final vowel is short, both candidates fare equally badly on FTBIN and, thus, it is not evident which output is optimal. We have selected the former parse on grounds that the final foot, as the only obligatory foot in both Clara's grammar and the target grammar, should be the one to respect FTBIN whenever possible. 
In sum, we have observed that Clara's outputs at early stages in development are consistent with a grammar where a binary iambic foot constrains both the minimal and maximal shape of her productions. The summary table in (20) charts the developmental path for PWds from Stages 1 to 5 (percentages provided are approximate).

(20) Summary of developmental patterns for PWds

\begin{tabular}{lll} 
& Stages 1-3 & Stages 4-5 \\
\hline Lower bound effects & $>85 \%$ outputs min one foot & $50 \%$ outputs min one foot \\
$(1 \sigma$ and $2 \sigma$ targets $)$ & $<15 \%$ subminimal outputs & $50 \%$ subminimal outputs \\
\hline Upper bound effects & $100 \%$ outputs max one foot & $50 \%$ outputs max one foot \\
(3 $\sigma$ targets) & & $20 \%$ unfooted syllables \\
& & $30 \%$ two-foot parses \\
\hline
\end{tabular}

At Stages 1-3, outputs are (virtually always) exactly one binary foot, so FTBIN, Exhaust(PWd) and AlignFoot are all undominated; segmental faithfulness constraints are low-ranking, yielding both augmentation and truncation as appropriate. At Stages 4-5, FTBIN plays a less decisive role. Concerning lower bound effects for one-syllable lexical targets $(1 \sigma$-lex and $1 \sigma$-fnc $+1 \sigma$-lex $)$, vowel lengthening is no longer commonly observed, with the important result that outputs no longer always respect word minimality. The ranking between DEP and all constraints against bimoraic syllables on the one hand and FTBIN on the other is thus unstable. Concerning upper bound effects, the behaviour at Stages 4-5 indicates that all three markedness constraints, FTBIN, Exhaust(PWd) and ALIGnFoot, play a less decisive role. The ranking between MAX and Exhaust(PWd) is no longer wellestablished, with the result that unfooted syllables are starting to be permitted; the ranking between MAX and FTBIN/ALIGNFOOT is similarly no longer well-established, with the result that two-foot parses are beginning to be produced.

\section{The lexical/functional split}

Section 5 has shown that the binary foot plays an important role in shaping Clara's outputs, especially at Stages 1-3. We turn now to examine whether the emergence of left-edge functional material can shed further light on the role of the foot in Clara's grammar.

Evidence for the foot in child French would come from a grammar which shows a clear difference in the treatment of lexical and functional material in three-syllable targets, because the prosodification of these two types of constructions differs, under the view that French respects an elaborated prosodic hierarchy (section 2.2). Recall that three-syllable lex targets like [atã'sjõ] attention 'watch out' are prosodified with the initial syllable parsed directly by the PWd (21a), while threesyllable fnc+lex targets like [la pu'pe] la poupée 'the doll' have the initial syllable organised outside the PWd as a free clitic (21b). 
(21) a. Lexical:

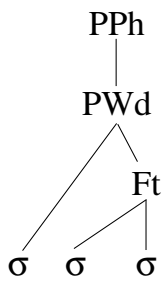

a tã 'sj̃̃ b. Functional + lexical:

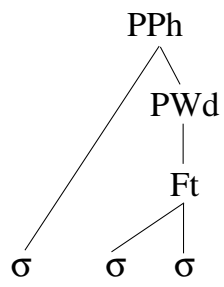

la pu 'pe

If Clara's grammar were to show truncation of $3 \sigma$-lex forms when three-syllable constructions shaped $1 \sigma$-fnc $+2 \sigma$-lex are produced more accurately, this would indicate that it is truly the foot that places an upper bound on the length of lexical words, rather than, for example, all three-syllable constructions being shortened due to processing or other cognitive demands. Importantly, the claim here is not that all children should show this pattern in development; it is rather that an asymmetry in this direction would support the hypothesis that it is the foot that plays a decisive role in shaping children's outputs.

Before we turn to the results, we must first address the formal status of putative function morphemes in Clara's grammar. There is a large literature on filler syllables, material which is produced in place of function words (see, e.g., Peters and Menn 1993, and the contributions to Journal of Child Language 28.1, 2001). Filler syllables reveal that learners are aware that, in the target language, lexical items are often preceded by additional material but they may not yet understand the syntax and semantics of this material. Some researchers may assume that filler syllables are prosodified internal to the lower PWd, that is, until the child shows definitive evidence of their morpho-syntactic function and target-approximate segmental shape; others who believe that function morphemes are appropriately represented in the syntax at the point when fillers appear in their place in production may assume that fillers are prosodified as are true fnc. In order not to bias the results one way or the other, we have removed forms containing what are indisputably fillers from the analysis of the lexical-functional split. Clara does not appear to produce many fillers, although this assessment rests largely on the criteria that one uses to distinguish fillers from true fnc (see esp. Veneziano and Sinclair 2000).

We will focus on Stage 3 in Clara's development. Recall from Table 5 that, at this stage, unfooted syllables in three-syllable lex targets are not permitted. Interestingly, Stage 3 is the point when proclitics begin to be produced by Clara (see also Parsons 2005). Determiners, prepositions and a few subject pronouns appear in short succession, suggesting that a prosodic rather than syntactic or semantic explanation holds for the change from Stage 2 to Stage 3; specifically, that the appearance of a range of proclitics provides evidence for the independence of the PWd and $\mathrm{PPh}$ in Clara's grammar. The latter view is supported by the observation that Stage 3 is also the point when phrases emerge (е.g., [belku'œь] $\rightarrow$ [ßei tu'logu] belle couleur 'pretty colour', [vwaspa'pa] $\rightarrow$ [ßарə'pæ] voir papa 'see dad'). 
Table 6. Lexical/functional split: Three-syllable targets at Stage 3 ( $\sigma$ is lexical; $\underline{\sigma}$ is functional).

\begin{tabular}{|c|c|c|c|c|c|c|c|c|}
\hline \multicolumn{4}{|c|}{ (A) Outputs for $3 \sigma$-lex targets } & \multicolumn{5}{|c|}{ (B) Outputs for $1 \sigma$-fnc $+2 \sigma$-lex targets } \\
\hline $\begin{array}{c}\mathrm{N}^{0} \\
\text { attemp }\end{array}$ & $\begin{array}{c}\text { Unfooted } \sigma \\
\sigma\left(\sigma^{\prime} \sigma\right)\end{array}$ & $\begin{array}{c}\text { Truncation } \\
(\sigma \delta)\end{array}$ & $\begin{array}{l}\text { 2-ft parses } \\
(\sigma)(\sigma \sigma)\end{array}$ & $\begin{array}{c}\mathrm{N}^{\mathbf{o}} \\
\text { attemp }\end{array}$ & $\begin{array}{l}\text { Unfooted } \sigma \\
\underline{\sigma}\left(\sigma^{\prime} \sigma\right)\end{array}$ & $\begin{array}{c}\text { Truncation } \\
(\sigma \sigma \sigma)\end{array}$ & $\begin{array}{c}\text { Truncation } \\
\underline{\sigma}(\sigma)\end{array}$ & $\begin{array}{c}\text { 2-ft parses } \\
(\underline{\sigma})\left(\sigma^{\prime} \sigma\right)\end{array}$ \\
\hline 3 & 0 & $\begin{array}{c}3 \\
(100 \%)\end{array}$ & 0 & 36 & $\begin{array}{c}14 \\
(39 \%)\end{array}$ & $\begin{array}{c}20 \\
(56 \%)\end{array}$ & $\begin{array}{c}2 \\
(5 \%)\end{array}$ & 0 \\
\hline
\end{tabular}

Table 6 compares the patterns for $3 \sigma$-lex targets (from Table 5) and three-syllable targets shaped $1 \sigma$-fnc $+2 \sigma$-lex; all counts for the latter are for obligatory contexts. It is immediately evident that these two types of three-syllable constructions pattern differently. While the columns under (A) show that $3 \sigma$-lex are largely avoided and, when attempted, always undergo truncation, the columns under (B) reveal that three-syllable targets shaped $1 \sigma$-fnc $+2 \sigma$-lex are produced intact $39 \%$ of the time. Truncation to a bisyllabic output is proportionately much less common in (B) because the lexical part of the target utterance is not longer than a foot, in contrast to the targets in (A). Seen another way, it is the difference in the prosodic organisation of $\sigma_{1}$ that is responsible for the different patterns of behaviour observed. Since $\sigma_{1}$ in the targets in (A) is internal to the constituent which organises the foot, it is subject to the constraints that regulate PWd well-formedness at this stage, namely that PWds are maximally one foot. Since $\sigma_{1}$ in the targets in (B) is outside of the PWd, is it not forced to delete to respect constraints on PWd size. In short, the different patterns observed in (A) and (B) provide evidence for three levels of the prosodic hierarchy, foot-PWd-PPh, and for constraints that regulate the size of PWds to an upper bound of one foot.

Examples of the two patterns of behaviour under focus for three-syllable targets shaped $1 \sigma$-fnc $+2 \sigma$-lex are in (22). Parallel examples for lex targets were provided in (18).

(22) Three-syllable targets shaped $1 \sigma$-fnc $+2 \sigma$-lex at Stage 3: Unfooted syllables vs. truncation

\begin{tabular}{|c|c|c|c|c|}
\hline Pattern: & Target: & Clara's output: & Orthography: & Gloss: \\
\hline$\underline{\sigma} \sigma \sigma \rightarrow \underline{\sigma}\left(\sigma^{\prime} \sigma\right)$ & $\begin{array}{l}\text { [ə̃wa'zo] } \\
\text { [dəpa'pa] }\end{array}$ & $\begin{array}{l}\text { [əwe'zu:] } \\
\text { [dıpa'pæ] }\end{array}$ & $\begin{array}{l}\text { un oiseau } \\
\text { de papa }\end{array}$ & $\begin{array}{l}\text { 'a bird' } \\
\text { 'of dad' }\end{array}$ \\
\hline $5 \sigma \rightarrow(\sigma \sigma)$ & $\begin{array}{l}\text { [ãmi'nu] } \\
\text { [ãbe'be] }\end{array}$ & $\begin{array}{l}\text { [mə'nu] } \\
\text { [bə'be: }]\end{array}$ & $\begin{array}{l}\text { un minou } \\
\text { un bébé }\end{array}$ & $\begin{array}{l}\text { 'a pussy-cat' } \\
\text { 'a baby' }\end{array}$ \\
\hline
\end{tabular}

Finally, it is worth noting that Clara attempts three cases of three-syllable targets shaped $1 \sigma$-fnc $+1 \sigma$-fnc $+1 \sigma$-lex at Stage 3 and none of these undergo truncation (e.g., [dãte'pje] $\rightarrow$ [at Ípji] dans tes pieds 'inside your feet'), again because not all syllables in the target form are internal to the PWd.

In sum, we have observed that Clara's grammar treats three-syllable constructions differently, depending on whether the first syllable is lexical or functional. 
This supports the position that lexical material is prosodified differently from functional material, the former inside the PWd, and the latter outside, linked directly to the PPh. The earlier emergence of three-syllable constructions shaped $1 \sigma$-fnc + $2 \sigma$-lex is consistent with the view that it is indeed the binary foot that serves to regulate the shape of Clara's lexical outputs, especially at Stage 3 and earlier.

In terms of ranking, Exhaust $(\mathrm{PWd})$ and $\operatorname{ExhausT}(\mathrm{PPh})$ are both undominated at Stages 1 and 2; all of Clara's PWds are limited to exactly one foot, and no left-edge clitics appear in outputs (although obligatory contexts for the latter do not emerge until Stage 2; see Table 1). At Stage 3, proclitics begin to appear, indicating that the ranking between EXHAUST(PPh) and MAX is unstable. MAX is still dominated by EXHAUST(PWd), however, with the result that no PWds contain an unfooted syllable at this stage in development. In short, the different rankings of Exhaust $(\mathrm{PWd})$ and Exhaust $(\mathrm{PPh})$ relative to MAX is what is responsible for the different treatment of lex vs. fnctlex targets in three-syllable constructions at Stage 3.

\section{Conclusion}

We began this paper by detailing the difficulties that French provides for the linguist in light of cross-linguistic observations about the constraints that govern stress systems. While the French system no doubt presents a serious challenge for the language learner, we have shown that, from the onset of production, Clara's grammar is regulated by cross-linguistically motivated constraints on prosodic well-formedness, including those that are not necessarily respected in the target grammar.

In particular, we have argued that the augmentation patterns displayed in Clara's early outputs reveal that her grammar respects foot binarity, even though this constraint is freely violable in target French. Clara's truncation patterns and differences in the treatment of lexical and functional material in three-syllable constructions further showed that the binary foot places an upper bound on her early PWds as well. Taken together, the lower and upper bound effects observed enabled us to conclude that Clara's grammar is much like the grammars of children learning other languages, languages with stress systems that are more amenable to standard constraints on prosodic well-formedness.

As we discussed, many of the properties of French stress have led researchers to question whether a foot projection can reasonably be motivated for the adult language. Consistent with this, we showed that a developing language which lacks the foot and which respects constraints on syllable and PWd well-formedness would lead to a preference for $\mathrm{CV}$ outputs, at the expense of faithfulness to input forms. Given that learners of many languages show a high proportion of CV outputs at the earliest stage in development, finding an adult language which does not have a foot projection would have led to a formal analysis of this otherwise intractable stage in acquisition.

Although adult French seemed like an excellent candidate for a foot-less language, we have instead argued that the facts of prominence in the language can be largely accommodated with standard assumptions on prosodic structure, notably 
including the foot. Once we admit a foot projection into French, however, we return to the challenge of formally accounting for the fact that the language contains rampant violations of word minimality. In spite of the ambient input to which Clara is exposed with its abundance of minimal word violations, her early outputs respect foot binarity. In conclusion, her early grammar supports a dominant role for markedness constraints in regulating the shape of children's outputs, even if satisfying these constraints leads to forms that are significantly different from those which are robustly attested in the target language.

\section{References}

Allen, George D. (1983). «Some suprasegmental contours in French two-year-old children's speech». Phonetica 40: 269-292.

Allen, George D.; Hawkins, Sarah (1978). «The development of phonological rhythm». In: Bell, Alan; Hooper, Joan B. (eds.), Syllables and Segments. Amsterdam: NorthHolland, pp. 173-185.

Archibald, John (1996). «The acquisition of syllable weight and foot type». Paper presented at the Fifth Conference on Laboratory Phonology, Northwestern University, July.

Archibald, John; Carson, Jana (2000). «Acquisition of Quebec French stress». Paper presented at the Annual Meeting of the Canadian Linguistic Association, University of Alberta, May.

Boysson-Bardies, Bénédicte de (1996). Comment la parole vient aux enfants. Paris: Éditions Odile Jacob.

Buckley, Meaghen (2004). «Linguistic Bootstrapping and the Syntax-Prosody Interface: The Syntax and Phonology of Clitics in Second Language French». McGill University, undergraduate honours thesis.

Charette, Monik (1991). Conditions on Phonological Government. Cambridge: Cambridge University Press.

Cardoso, Walcir (2003). Topics in the Phonology of Picard. McGill University, doctoral dissertation.

Curtin, Suzanne (2001). Representational Richness in Phonological Development. University of Southern California, doctoral dissertation.

Delattre, Pierre (1966). «A comparison of syllable length conditioning among languages». International Review of Applied Linguistics in Language Teaching IV: 183-198.

Dell, François (1984). «L'accentuation dans les phrases en français». In: Dell, François; Hirst, Daniel; Vergnaud, Jean-Roger (eds.), Forme sonore du langage. Paris: Hermann, pp. 65-122.

Demuth, Katherine (1995). «Markedness and the development of prosodic structure». In: Beckman, Jill N. (ed.), Proceedings of the North East Linguistic Society 25: 13-25. Amherst, Mass: Graduate Linguistic Student Association.

- (2001). «Prosodic constraints on morphological development». In: Weissenborn, Jürgen; Höhle, Barbara (eds.), Approaches to Bootstrapping: Phonological, Lexical, Syntactic and Neurophysiological Aspects of Early Language Acquisition. Vol. 2. Amsterdam: Benjamins, pp. 3-21. 
Demuth, Katherine; Fee, E. Jane (1995). «Minimal words in early phonological development». Ms., Brown University and Dalhousie University.

Demuth, Katherine; Johnson, Mark (2003). «Truncation to subminimal words in early French». Canadian Journal of Linguistics 48: 211-241.

Deville, Gérard (1891). «Notes sur le développement du langage II». Revue de linguistique et de philologie comparée 24: 10-42, 128-143, 242-257, 300-320.

Echols, Catharine; Newport, Elissa (1992). «The role of stress and position in determining first words». Language Acquisition 2: 189-220.

Fikkert, Paula (1994). On the Acquisition of Prosodic Structure. The Hague: Holland Academic Graphics.

Fouché, Pierre (1934). «Évolution phonétique du français du XVI siècle à nos jours». Le français moderne 2: 217-236.

Garde, Paul (1968). L'accent. Paris: Presses Universitaires de France.

Gendron, Jean-Denis (1966). Tendances phonétiques du français parlé au Canada. Québec: Les Presses de l'Université Laval.

Gerken, LouAnn (1994). «A metrical template account of children's weak syllable omissions from multisyllabic words». Journal of Child Language 21: 565-584.

Gnanadesikan, Amalia (2004). «Markedness and Faithfulness constraints in child phonology». In: Kager, René; Pater, Joe; Zonneveld, Wim (eds.), Constraints in Phonological Acquisition. Cambridge: Cambridge University Press, pp. 73-108. Available (1995) as ROA-67 from http://roa.rutgers.edu.

Goad, Heather (1996). «Codas, word-minimality, and empty-headed syllables». In: Clark, Eve (ed.), Child Language Research Forum 28: 113-122. Stanford: Center for Language and Information.

- (2002). «Markedness in right-edge syllabification: Parallels across populations». Canadian Journal of Linguistics 47: 151-186.

Gordon, Matthew (2002). «A factorial typology of quantity-insensitive stress». Natural Language \& Linguistic Theory 20: 491-552.

Hallé, Pierre; Boysson-Bardies, Bénédicte de; Vihman, Marilyn (1991). «Beginnings of prosodic organization: Intonation and duration patterns of disyllables produced by Japanese and French infants». Language and Speech 34: 299-318.

Hayes, Bruce (1995). Metrical Stress Theory: Principles and Case Studies. Chicago: University of Chicago Press.

Ingram, David (1978). «The role of the syllable in phonological development». In: Bell, Alan; Hooper, Joan B. (eds.), Syllables and Segments. Amsterdam: North-Holland, pp. 143-155.

Jakobson, Roman (1941). Child Language, Aphasia and Phonological Universals. The Hague: Mouton. Translated 1968 by Allan R. Keiler.

Jun, Sun-Ah; Fougeron, Cécile (2000). «A phonological model of French intonation». In: Botinis, Antonis (ed.), Intonation: Analysis, Modelling and Technology. Dordrecht: Kluwer, pp. 209-242.

Kehoe, Margaret; Stoel-Gammon, Carol (1997). «The acquisition of prosodic structure: An investigation of current accounts of children's prosodic development». Language 73: 113-144.

Lleó, Conxita (1997). «Filler syllables, proto-articles and early prosodic constraints in Spanish and German». In: Sorace, Antonella; Heycock, Caroline; Shillcock, Richard (eds.), Language Acquisition: Knowledge, Representation and Processing. 
Proceedings of the GALA '97 Conference on Language Acquisition. Human Communication Research Centre, University of Edinburgh, pp. 251-256.

- (2002). «The role of markedness in the acquisition of complex prosodic structures in German-Spanish bilinguals». International Journal of Bilingualism 6: 291-313.

- (2003). «Child prosody and filler syllables: Looking into Spanish through the optimal window of acquisition». In: Montrul, Silvina; Ordóñez, Francisco (eds.), Linguistic Theory and Language Development in Hispanic Languages. Papers from the 5th Hispanic Linguistics Symposium and the 4th Conference on the Acquisition of Spanish and Portuguese. Somerville, Mass: Cascadilla Press, pp. 229-253.

McCarthy, John; Prince, Alan (1986). «Prosodic Morphology». Ms., University of Massachusetts Amherst and Brandeis University.

- (1990). «Foot and word in prosodic morphology: The Arabic broken plural». Natural Language \& Linguistic Theory 8: 209-282.

Mertens, Piet (1987). L'intonation du français. De la description linguistique à la reconnaissance automatique. Katholieke Universiteit Leuven, doctoral dissertation.

Nespor, Marina; Vogel, Irene (1986). Prosodic Phonology. Dordrecht: Foris.

Ota, Mits (1999). Phonological Theory and the Acquisition of Prosodic Structure: Evidence from Child Japanese. Georgetown University, doctoral dissertation.

Ouellet, Marise; Thibault, Linda (1996). «L'allongement prétonique: un phénomène opportuniste?». In: Dolbec, Jean; Ouellet, Marise (eds.), Recherches en phonétique et en phonologie au Québec. Québec: CIRAL, pp. 47-61.

Paradis, Claude; Deshaies, Denise (1990). «Rules of stress assignment in Québec French: Evidence from perceptual data». Language Variation and Change 2: 135-154.

Paradis, Johanne (2001). «Do bilingual two-year-olds have separate phonological systems?» International Journal of Bilingualism 5: 19-38.

Paradis, Johanne; Petitclerc, Sophie; Genesee, Fred (1997). «Word truncation in Frenchspeaking two year olds». In: Hughes, Elizabeth; Hughes, Mary; Greenhill, Annabel (eds.), Proceedings of the 21st Annual Boston University Conference on Language Development. Somerville, Mass: Cascadilla Press, pp. 441-452.

Parsons, Jennifer (2005). «Acquisition of the Prosodic Word». Ms., Memorial University of Newfoundland.

Pater, Joe (1997). «Minimal violation and phonological development». Language Acquisition 6: 201-253.

Pater, Joe; Werle, Adam (2003). «Direction of assimilation in child consonant harmony». Canadian Journal of Linguistics 48: 385-408.

Peters, Ann; Menn, Lise (1993). «False starts and filler syllables: ways to learn grammatical morphemes». Language 69: 742-777.

Post, Brechtje (2003). «French phrasing and accentuation in different speaking styles». In: Grabe, Esther; Wright, David G.S. (eds.), Oxford University Working Papers in Linguistics, Philology and Phonetics 8: 69-83.

Rose, Yvan (2000). Headedness and Prosodic Licensing in the L1 Acquisition of Phonology. McGill University, doctoral dissertation.

- (2002). «Place specification and segmental distribution in the acquisition of wordfinal consonant syllabification». Canadian Journal of Linguistics 48: 409-435.

Rose, Yvan; dos Santos, Christophe (2004). «Prosodic domains and the acquisition of French phonology». Paper presented at the Second Lisbon Meeting on Language Acquisition, June. 
Schwartz, Richard G.; Leonard, Larry B. (1982). «Do children pick and choose? An examination of phonological selection and avoidance». Journal of Child Language 9: 319-336.

Scullen, Mary Ellen (1997). French Prosodic Morphology: A Unified Account. Bloomington: Indiana University Linguistics Club.

Selkirk, Elisabeth O. (1984). Phonology and Syntax: The Relation between Sound and Structure. Cambridge, Mass: MIT Press.

- (1986). «On derived domains in sentence phonology». Phonology 3: 371-405.

- (1996). «The prosodic structure of function words». In: Morgan, James; Demuth, Katherine (eds.), Signal to Syntax: Bootstrapping from Speech to Grammar in Early Acquisition. Mahwah, NJ: Lawrence Erlbaum, pp. 187-213.

Smolensky, Paul (1996). «The comprehension/production dilemma in child language». Linguistic Inquiry 27: 720-731.

Stampe, David (1969). «The acquisition of phonetic representation». Chicago Linguistic Society 5: 433-444.

Tremblay, Annie (in press). «Prosodic constraints on the production of grammatical morphemes in early French: The case of determiners.» In: Deen, Kamil Ud; Nomura, Jun; Schulz, Barbara; Schwartz, Bonnie (eds.), Proceedings of the Inaugural Conference on Generative Approaches to Language Acquisition-North America. University of Connecticut Occasional Papers in Linguistics 4.

Veneziano, Edy; Sinclair, Hermine (2000). «The changing status of 'filler syllables' on the way to grammatical morphemes». Journal of Child Language 27: 461-500.

Verluyten, S. Paul (1982). Investigation on French Prosodics and Metrics. Universiteit Antwerpen, doctoral dissertation.

Vijver, Ruben van de (1998). The Iambic Issue: Iambs as a Result of Constraint Interaction. The Hague: Holland Academic Graphics.

Walker, Douglas C. (1984). The Pronunciation of Canadian French. Ottawa: University of Ottawa Press.

Wijnen, Frank; Krikhaar, Evelien; den Os, Els (1994). «The (non)realization of unstressed elements in children's utterances: Evidence for a rhythmic constraint». Journal of Child Language 21: 59-83. 